\title{
RSW-MCFP: A Resource-Oriented Solid Waste Management System for a Mixed Rural-Urban Area through Monte Carlo Simulation-Based Fuzzy Programming
}

\author{
P. Li, ${ }^{1}$ H. J. Wu, ${ }^{1}$ and B. Chen ${ }^{1,2}$ \\ ${ }^{1}$ Northern Region Persistent Organic Pollution Control (NRPOP) Laboratory, Faculty of Engineering and Applied Science, \\ Memorial University of Newfoundland, St. John's, NL, Canada A1B 3X5 \\ ${ }^{2}$ Key Laboratory of Regional Energy and Environmental Systems Optimization, Ministry of Education, \\ Resources and Environmental Research Academy, North China Electric Power University, Beijing 102206, China
}

Correspondence should be addressed to B. Chen; bchen@mun.ca

Received 19 February 2013; Accepted 14 April 2013

Academic Editor: Guohe Huang

Copyright (C) 2013 P. Li et al. This is an open access article distributed under the Creative Commons Attribution License, which permits unrestricted use, distribution, and reproduction in any medium, provided the original work is properly cited.

The growth of global population and economy continually increases the waste volumes and consequently creates challenges to handle and dispose solid wastes. It becomes more challenging in mixed rural-urban areas (i.e., areas of mixed land use for rural and urban purposes) where both agricultural waste (e.g., manure) and municipal solid waste are generated. The efficiency and confidence of decisions in current management practices significantly rely on the accurate information and subjective judgments, which are usually compromised by uncertainties. This study proposed a resource-oriented solid waste management system for mixed rural-urban areas. The system is featured by a novel Monte Carlo simulation-based fuzzy programming approach. The developed system was tested by a real-world case with consideration of various resource-oriented treatment technologies and the associated uncertainties. The modeling results indicated that the community-based bio-coal and household-based $\mathrm{CH}_{4}$ facilities were necessary and would become predominant in the waste management system. The $95 \%$ confidence intervals of waste loadings to the $\mathrm{CH}_{4}$ and bio-coal facilities were 387, 450 and 178, 215 tonne/day (mixed flow), respectively. In general, the developed system has high capability in supporting solid waste management for mixed rural-urban areas in a cost-efficient and sustainable manner under uncertainty.

\section{Introduction}

Solid waste is causing significant environmental problems in urban and suburban areas and consequently leading to numerous adverse health and environmental impacts around the world [1]. The concerns in handling and disposing solid waste are growing with the continuous increases of waste generation in the world, which is closely correlated with the growth of population and the economy [2]. Due to the rising waste generation rates and the lack of available space in landfills, urban communities and even some rural areas are facing some critical challenges in developing effective solid waste management systems particularly and partly due to the existence of various uncertainties in the system $[3,4]$. These uncertainties may arise from a variety of possible sectors including waste generation rates, disposal capacity, treatment costs, and their interactions, as well as other general uncertainty sources such as incomplete information, measurement and sampling errors, subjective judgement, assumptions and approximation, and dynamics of environmental conditions [5-8]. These uncertainties affect the relative optimization and decision making processes, leading to significant complexities and compromising the confidence and efficiency of decisions [4, 9-11].

To address challenges from uncertainties, a number of optimization methods have been developed to handle different types of uncertainties in solid waste management in the past decades. Among these methods fuzzy programming and stochastic programming are widely reported in the literature $[4,8,12-19]$. Fuzzy techniques can be used to express the possibilistic uncertainties where vagueness of parameters is 
characterized by membership functions [16, 20, 21]; stochastic techniques are able to handle the probabilistic uncertainties where the probability distributions can be used to represent random variability of parameters [22-24]. Nevertheless, both techniques have their own drawbacks: membership functions may lead to a loss of information when inappropriate subjective judgments have been made and/or when some parameters can be better represented by stochastic variables, while defining of probability distribution can be affected by the limited amount of data [20, 21, 25]. Furthermore, possibilistic and probabilistic uncertainties can frequently coexist in environmental systems such as municipal solid waste (MSW) management systems. It is necessary to develop integrated fuzzy and stochastic techniques to handle such cases, and one attempt has previously been made [26]. However, some difficulties have been reported in finding effective linkages between these two techniques and in appropriately interpreting optimized results from their outputs. For example, fuzzification and defuzzification are challenging when the stochastic distributions are involved. Thus, possibilistic and probabilistic uncertainties are usually treated separately $[2,20,21,27,28]$.

Recently, some approaches have been developed to simultaneously deal with possibility and probability $[4,29,30]$. However, these approaches treat probabilistic uncertainties based on limited, discrete probability distributions and are unable to simultaneously handle continuous probability and subjective information $[2,21]$. In practice, system variables usually include both subjective and objective information (or dual uncertainties) [2,31]; therefore, the incorporation of fuzzy set theory and Monte Carlo simulation becomes necessary and valuable [21, 32, 33]. Monte Carlo simulation can address continuous probabilistic uncertainties by using probability density functions (PDFs) [34-36]. Therefore, the integration of fuzzy programming approaches with Monte Carlo simulation can be promising in addressing the limitations of treating possibilistic and continuous probabilistic uncertainties. However, challenges still remain in finding optimal solutions to the new coupled problem of the fuzzy programming and Monte Carlo simulation.

Furthermore, it is significantly difficult to design a successful solid waste management system due to complexities and uncertainties, especially in mixed rural-urban areas. These areas face a special challenge in treating and disposing agricultural residues and livestock manure, which may have much higher loadings than the common MSW stream. At the same time, manure can also be a potential valuable resource through resource-oriented recovery techniques (such as composting, $\mathrm{CH}_{4}$ generation, and bio-coal generation). Unlike traditional solid waste management systems which treat the solid waste as burden, the resourceoriented solid waste management system treats it as potential resources or materials that can be used for reproduction. Under this perspective, the solid waste management system can be sustainably run by profit driven sectors rather than difficultly maintained by cost controlling from some administrative departments, and therefore can be easily controlled by the market $[2,8]$. Therefore, resource-oriented solid waste management is a promising and potentially a preferred solution in the future. The resource-oriented concept is especially important for mixed rural-urban areas where livestock breeding exists. It can minimize environmental impacts with maximizing the economic benefits for mixed rural-urban areas and increase the motivation of application by different sectors (e.g., government and industry) [2, 37]. Although there are some attempts in applying resource-oriented waste management methods for industrial solid waste, studies targeting agricultural and municipal solid waste in mixed rural-urban areas are still insufficient $[2,38]$.

The Monte Carlo simulation-based fuzzy programming (MCFP) model is a new mathematical approach which has been recently developed [2]. However, the previous study only applied a simplified hypothetical case without further testing, particularly by real-world problems. In this study, the MCFP model is further defined with a resource-oriented solid waste management concept, to form a resource-oriented solid waste management system supported by Monte Carlo simulation-based fuzzy programming (RSW-MCFP) system for better supporting solid waste management in mixed ruralurban areas when possibilistic and continuous probabilistic uncertainties coexist in real-world applications. Another key objective of this new method is to reduce the amount of solid waste by recovering materials and energy from solid waste. In short, the objectives of this study are (1) to develop a resource-oriented solid waste management system for a mixed rural-urban area supported by a Monte Carlo simulation-based fuzzy programming (RSW-MCFP) and (2) to conduct feasibility and efficiency tests as well as a tradeoff analysis through a real-world case study of solid waste management in the town of Shuangcheng in Northeast China. This approach is expected to efficiently handle various uncertainties in a complex system with fewer additional constraints and provide a powerful tool to generate a set of feasible decision alternatives for local decision makers to improve the efficiency and confidence in managing solid waste in mixed rural-urban areas.

\section{Methodology}

In the MCFP approach, a Monte Carlo simulation approach is introduced to handle the probabilistic uncertainties (continuous and discrete) [2]. By assigning random values to the uncertain parameters, the probabilistically uncertain information becomes deterministic one in a single loop of Monte Carlo simulation. Consequently, the original problem with dual uncertainties (coexistence of possibilistic and continually probabilistic uncertainties) becomes a fuzzy problem. Subsequently, a fuzzy programming approach based on the fuzzy-stochastic-interval linear programming (FSILP) method [10] is introduced to handle the possibilistic uncertainties, converting the fuzzy problem into a conventional linear problem.

In the FSILP approach, the Nguyen's method is used to convert the fuzzy and/or fuzzy stochastic linear programming problems into the conventional linear programs (LPs), by measuring the attainment values of fuzzy numbers and/or fuzzy random variables, as well as the superiority and inferiority between triangular fuzzy numbers/triangular fuzzy 
stochastic variables [39]. An attainment value is a degree of attainment of the fuzzy goal. It is considered to be a concept similar to a degree of satisfaction of the fuzzy decision when the fuzzy constraint is replaced by the fuzzy expected payoff. It can also be interpreted as a possibility of attainment of the fuzzy goal. The FSILP approach is advanced from the Nguyen method [39] in different situations of relations in demand (left-hand-side, LHS) and resource (right-hand-side, RHS) as well as the introduction of interval programming. Although the FSILP approach is capable of handling the coexistence of uncertainties, its efficiency will decrease when the number of discrete probabilities increases. In addition, when the probabilistic uncertainty is described as a continuous distribution, integration is required in numerically processing the optimization, leading to difficulties. Furthermore, some of the distributions may not be integrable, making the optimization unachievable.

Monte Carlo simulation is a class of computation intensive algorithms based on randomization. These methods can provide near equivalent results to deterministic algorithms, making it a complement to the theoretical derivations. Monte Carlo simulation is especially suitable for problems with multiple probability distributions, while handling these distributions becomes complicated if using numerical methods. Due to incomplete or insufficient information from the literature and historical data as well as the subjective judgement, many input parameters are difficult to characterize by utilizing probability distributions for numerical applications. In many cases, the obtained probability distribution may be still uncertain where each data point contains a degree of belief, leading to dual uncertainties of possibility and continuous probability [29]. Consequently, in order to effectively tackle such dual uncertainties, fuzzy programming and Monte Carlo simulation need to be combined. However, the fuzzification and defuzzification processes in the conventional fuzzy programming are still difficult in such integration.

The FSILP approach can easily convert a fuzzy problem into a crisp deterministic problem without conventional fuzzification and defuzzification processes, which makes it significantly easier in coupling with the Monte Carlo simulation. The random values of the parameters are firstly assigned in each Monte Carlo simulation trial according to the probability distributions of parameters. Therefore, the parameters with probabilistic uncertainties become deterministic in a single loop of Monte Carlo simulation, leaving possibilistic uncertainties in the problem and leading to a fuzzy problem. Such fuzzy problem is then solved by the fuzzy programming from the FSILP approach. Finally, a group of solutions can be collected to present the most frequent occurrences of results under the different kinds of uncertainties in parameters.

Consider a fuzzy stochastic linear problem as follows:

$$
\begin{array}{ll}
\min & f=C X \\
\text { s.t. } & \sum_{j=1}^{n}\left(\widetilde{A}_{i j}\right)_{w} X_{j} \leq\left(\widetilde{B_{i}}\right)_{w}, \quad i=1, \ldots, m \\
& X_{j} \geq 0, \quad w \in \Omega
\end{array}
$$

where $C \in\{R\}^{1 \times n}$ is the matrix of coefficients in the objective function and $\left(\widetilde{A}_{i j}\right)_{w} \in\{R\}^{m \times n},\left(\widetilde{B}_{i}\right)_{w} \in\{R\}^{m \times 1}$ are matrices of constraint coefficients with fuzzy random variables defined on a probability space $(\Omega, F, P)$. Assume that all fuzzy numbers are in a form of $\widetilde{t}=\left(t, \delta^{-}, \delta^{+}\right)$, where $\delta^{-}$and $\delta^{+}$are the lower and upper spreads of the membership function as follows:

$$
\begin{gathered}
X_{i}=\left\{\tilde{t} ; \tilde{t}=\left(t, \delta^{-}, \delta^{+}\right), \delta^{-}, \delta^{+} \geq 0\right\} \\
\mu_{\tilde{t}}\left(X_{i}\right)= \begin{cases}\max \left(0,1-\frac{t-y}{\delta^{-}}\right), & \text {if } y \leq t \\
1, & \text { if } a=0, b=0, t=y \\
\max \left(0,1-\frac{y-t}{\delta^{+}}\right), & \text {if } y \leq t \\
0, & \text { otherwise. }\end{cases}
\end{gathered}
$$

According to the Monte Carlo simulation, deterministic values for parameters will be assigned to all the random variables in each trial (the $l$ th trial) out of $N$ trials based on the distributions of the parameters. Therefore, for the $l$ th trial,the Problem (1a)-(1c) can be converted to a fuzzy problem as follows:

$$
\begin{array}{ll}
\min & f=C X \\
\text { s.t. } & \sum_{j=1}^{n}\left(\widetilde{A}_{i j}\right)_{l} X_{j} \leq\left(\widetilde{B}_{i}\right)_{l}, \quad i=1, \ldots, m, l=1, \ldots, N \\
& X_{j} \geq 0,
\end{array}
$$

where $\left(\widetilde{A}_{i j}\right)_{l} \in\{R\}^{m \times n},\left(\widetilde{B}_{i}\right)_{l} \in\{R\}^{m \times 1}$ are the matrices of constraint coefficients with fuzzy variables defined on a series of fuzzy membership functions with the assigned random variables in the $l$ th trial.

According to the fuzzy programming from the FSILP approach, the fuzzy terms in the Problem (4a)-(4c) can be converted as follows [10]:

$$
\begin{array}{r}
\min f=C X+\sum_{i=1}^{u} \lambda_{i}^{1}-\sum_{k=1}^{v} \lambda_{k}^{2} \\
\text { s.t. } \quad \frac{1}{2}\left(\sum_{j=1}^{n}\left(\left(\widetilde{A}_{i j}^{1}\right)_{w} X_{j}+\delta_{x_{j}}^{+} X_{j}\right)\right. \\
\left.+\delta_{B_{i}^{1}}^{-}+S_{i}-\left(\widetilde{B}_{i}^{1}\right)_{w}\right)=\lambda_{i}^{1}, \\
i=1, \ldots, u \\
\frac{1}{2}\left(\sum_{j=1}^{n}\left(\left(\widetilde{A}_{k j}^{2}\right)_{w} X_{j}-\delta_{x_{j}}^{-} X_{j}\right)\right. \\
\left.-\delta_{B_{k}^{2}}^{+}-\left(\widetilde{B}_{k}^{2}\right)_{w}\right)=\lambda_{k}^{2}, \\
k=1, \ldots, v
\end{array}
$$




$$
\begin{gathered}
\lambda_{i}^{1} \leq \frac{1}{2}\left(\sum_{j=1}^{n} \delta_{x_{j}}^{+} X_{j}+\delta_{B_{i}^{1}}^{-}\right) \\
\lambda_{k}^{2} \leq \frac{1}{2}\left(\sum_{j=1}^{n} \delta_{x_{j}}^{-} X_{j}+\delta_{B_{k}^{2}}^{+}\right) \\
X_{j}, \delta_{x_{j}}^{-}, \delta_{x_{j}}^{+}, \delta_{B_{i}^{1}}^{-}, \delta_{B_{k}^{1}}^{+}, \lambda_{i}^{1}, \lambda_{k}^{2}, p_{i}^{1}, p_{k}^{2}, S_{i} \geq 0, \\
w \in \Omega,
\end{gathered}
$$

where $\lambda_{i}^{1} \in\{R\}^{u \times 1}$ and $\lambda_{k}^{2} \in\{R\}^{v \times 1}$ are matrices of control decision variables corresponding to the degree (membership grade) to which $X$ solution fulfils the fuzzy constraints; $\widetilde{A}_{i j} \in$ $\{A\}^{u \times n}$ and $\widetilde{A}_{k j}^{2} \in\{A\}^{v \times n}$ are matrices of positive and negative coefficients in the constraint, respectively; $\widetilde{B}_{i}^{1} \in\{R\}^{u \times 1}$ and $\widetilde{B}_{k}^{2} \in\{R\}^{v \times 1}$ are matrices of positive and negative RHS; and $S_{i} \in\{R\}^{m \times 1}$ is the matrix of the slack variables. Furthermore, the constraints of $\lambda_{i}^{1} \leq(1 / 2)\left(\sum_{j=1}^{n} \delta_{x_{j}}^{+} X_{j}+\delta_{B_{i}^{1}}^{-}\right)$and $\lambda_{k}^{2} \leq$ $(1 / 2)\left(\sum_{j=1}^{n} \delta_{x_{j}}^{-} X_{j}+\delta_{B_{k}^{2}}^{+}\right)$are added because $\lambda$ represents the attainment of the memberships of LHS and RHS which is also equivalent to the overlap of these two memberships on one side spread.

After $N$ trials are finished, the sets of results can be obtained as follows:

$$
\begin{aligned}
f_{l, \mathrm{opt}} & =\left\{f\left(X_{j l, \mathrm{opt}}\right) ; X_{j l, \mathrm{opt}} \geq 0\right\}, \\
l & =1, \ldots, M ; \quad j=1, \ldots, Z,
\end{aligned}
$$

where $M$ is the number of the feasible solutions after $N$ trials of the Monte Carlo simulation, and $Z$ is the number of decision variables.

Assume that there is no uncertainty existing in the coefficients of the objective function $(C)$; the final solution can be stated as follows [2]:

$$
\begin{array}{r}
E\left(f_{\mathrm{opt}}\right)=\left\{f\left(E\left(X_{j, \mathrm{opt}}\right)\right) ; E\left(X_{j, \mathrm{opt}}\right) \geq 0\right\}, \\
l=1, \ldots, M .
\end{array}
$$

The full details about the MCFP approach as well as the solution algorithms can be found in [2].

\section{The MSW-MCFP System}

3.1. System Analysis for the Solid Waste Management in the Town of Shuangcheng. The city of Shuangcheng is a countylevel city under the administration of Harbin, the capital city of Heilongjiang Province in Northeast China. The city has $2,200 \mathrm{~km}^{2}$ of cropland and is ranked as one of the top five crop production bases in China. The livestock and dairy sectors are rapidly developing and becoming dominant industries in the city.

There are more than 290,000 cows on dairy farms in the city, making it an important location for dairy livestock breeding in China. However, the fast growth of livestock has not been accompanied with appropriate regulations, management practices, and treatments/disposal of manure and wastewater from dairy farms. Consequently, most of the livestock manure, is dumped at various locations surrounding the villages, occupying large land areas, releasing bad odour, and even burying and blocking roads. Properly managing rural waste, especially livestock manure has been identified as a top priority by the local governments, the agrofood industry, and the public.

This study targets the town of Shuangcheng, which is the administrative and economic centre of the city of Shuangcheng and also a mixed rural-urban area. According to the historical census of the town, the information about household, population, natural growth rate, and cattle stocks from 2000 to 2007 is collected [40]. The number of households ranges from 65,053 to 76,561 , and the mean value is 69,859 with standard deviation of 4,382 . The population ranges from 181270 to 183206 , and the mean value is 181,838 with standard deviation of 599 . The natural growth rate ranges from $1.33 \%$ to $6.54 \%$, and the mean value is 4.84 with standard deviation of 1.81 . The number of cattle ranges from 12,689 to 22,636 , and the mean value is 17,959 with standard deviation of 3,613 . It is estimated that the ratio of population between the urban and rural areas in the town is $2: 1$ [40]. Correspondingly, based on the assumption that the future growth rate of population remains the same level as the period from 2000 to 2007, the distributions for the population and cattle number within the planning period (2011-2015) can be determined (Figure 1).

It is reported that the generation rate of MSW in the rural area is 0.55 to $0.65 \mathrm{~kg}$ per capita per day, and which in the urban area is 1.1 to $1.3 \mathrm{~kg}$ per capita per day [41, 42]. Furthermore, the generation rate of manure from cattle is 5 to $15 \mathrm{~kg}$ per cattle per day [41, 42]. By involving possibility uncertainty, the membership functions for the loading of MSW and cattle manure are shown in Figure 2. For the sake of simplicity, symmetric triangular fuzzy numbers are used.

3.2. Development of a Resource-Oriented Solid Waste Management System. According to the system analysis (e.g., parameters and their functions as well as interactions among them) of the current situation of solid waste management, a system framework for resource-oriented solid waste management is proposed for the town of Shuangcheng (Figure 3). Over the 5-year planning period (2011-2015), the existing landfill and composting facilities will be available to meet the requirement of MSW treatment and disposal. Detailed operational and economic information has been collected in Tables 1 and 2 [40], including capacities, operation and maintenance costs, residue rates, revenues, and transportation costs of the proposed facilities (i.e., community-based bio-coal production and composting, household-based $\mathrm{CH}_{4}$ generation and composting). Finally, a penalty rate of $\$ 500 /$ tonne waste is assigned for dumping solid waste in nondesignated areas.

Currently, the most critical and challenging problem in the mixed rural-urban area of the town of Shuangcheng is how to deal with a huge amount of livestock manure (especially cow dung). In the proposed system, manure can be utilized for the methane generating, composting and bio-coal manufacturing. After this, only a small residual is left and can 


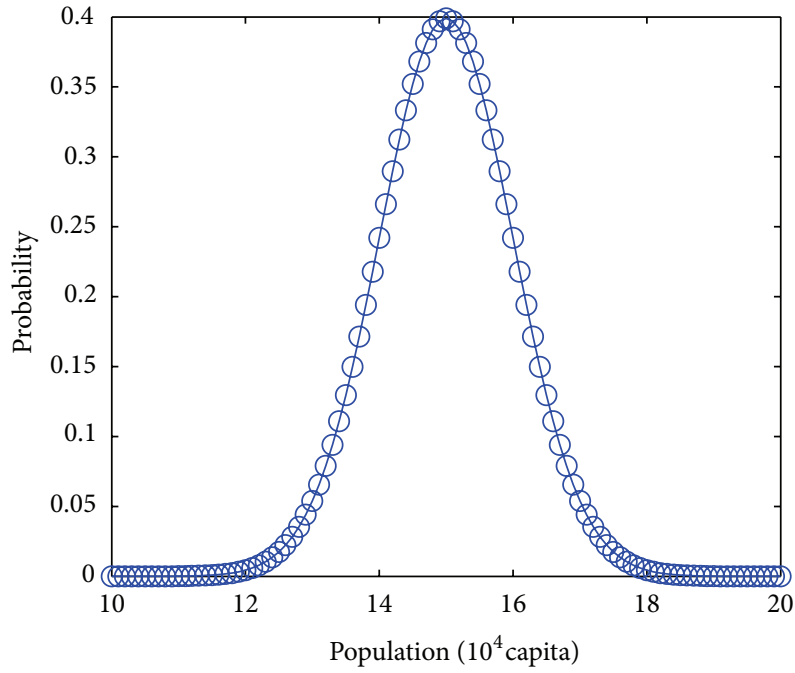

(a)

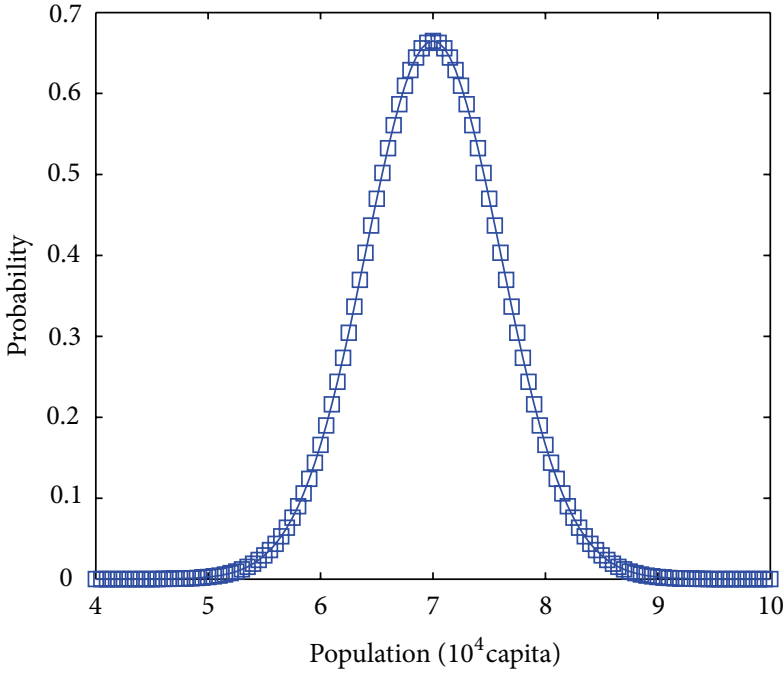

(b)

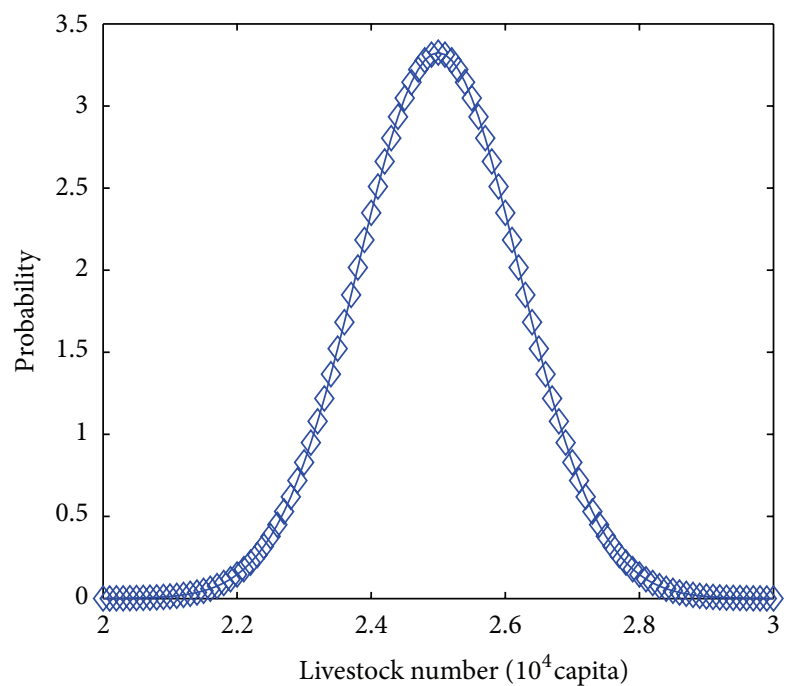

(c)

FIGURE 1: Probability distributions of the annual population from the (a) urban and (b) rural areas as well as (c) the number of livestock in the town of Shuangcheng from 2011 to 2015.

be used as fertilizer for farming, leading to substantial reduction of solid waste in the system. Furthermore, individual farmers can be driven by market incentives and form small firms to collect waste and send them to the waste treatment facilities such as composting plants and bio-coal generating plants. As a result, the farmers can get direct benefits from selling or collecting cattle manure; meanwhile, the treatment plants can generate profits by selling products or service (e.g., compost, bio-coal, and $\mathrm{CH}_{4}$ ).

An assumption is placed that the demands of the corresponding products or services in the market are much higher than the production from the system. After the collectors transfer the dung to enterprises, products such as the organic fertilizer, methane, and bio-coal can be sold back to farmers. Since the costs of these products are postulated to be less than the chemical fertilizers or coal and electricity, the farmers may save their money by utilizing these recycled products and therefore increase their incomes.
3.3. Development of an MCFP Approach to Support Solid Waste Management. According to the proposed resourceoriented solid waste management system and the collected information, the corresponding optimization model can be developed as follows:

$$
\begin{aligned}
\operatorname{minimize} \quad f= & \sum_{i=1}^{2} \sum_{j=1}^{5}\left(\mathrm{OP}_{j}+\mathrm{TR}_{i j}\right) x_{i j} \\
& +\sum_{j=1}^{5}\left(\mathrm{OP}_{j}+\mathrm{TR}_{2 j}\right) y_{j} \\
& +\sum_{i=1}^{2} \sum_{j=2}^{5}\left(\mathrm{OP}_{1}+\mathrm{TRL}_{j}\right) \mathrm{RM}_{j} x_{i j} \\
& +\sum_{j=2}^{5}\left(\mathrm{OP}_{1}+\mathrm{TRL}_{j}\right) \mathrm{RC}_{j} y_{j}
\end{aligned}
$$




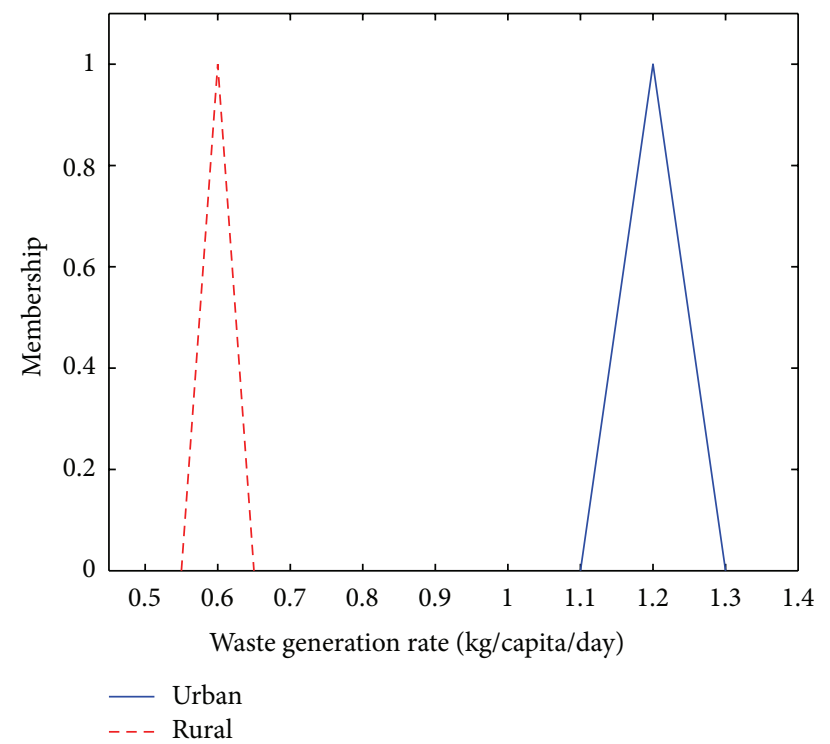

(a)

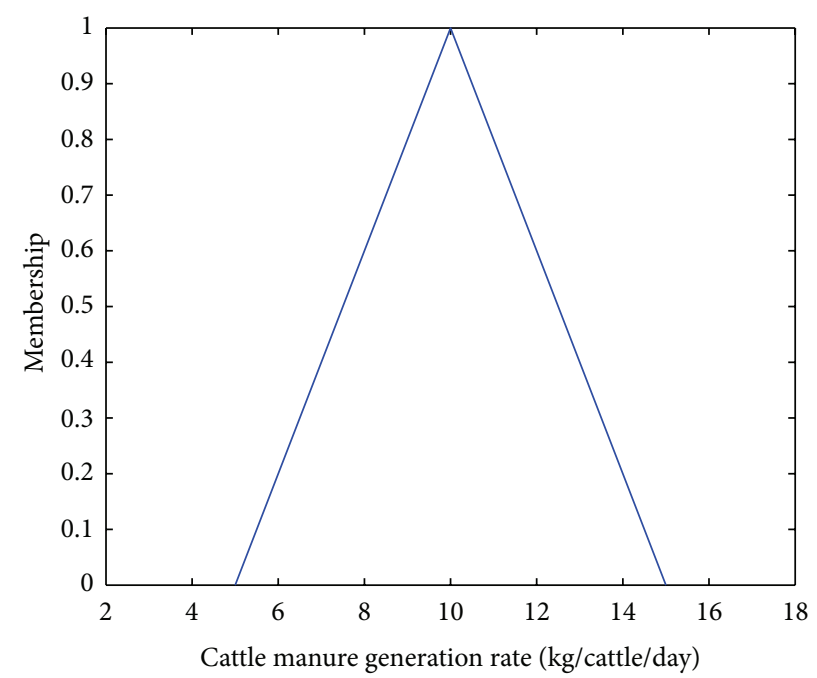

(b)

FIGURE 2: Fuzzy membership functions of (a) the MSW loadings from the urban and rural areas and (b) the cattle manure in the town of Shuangcheng from 2011 to 2015.

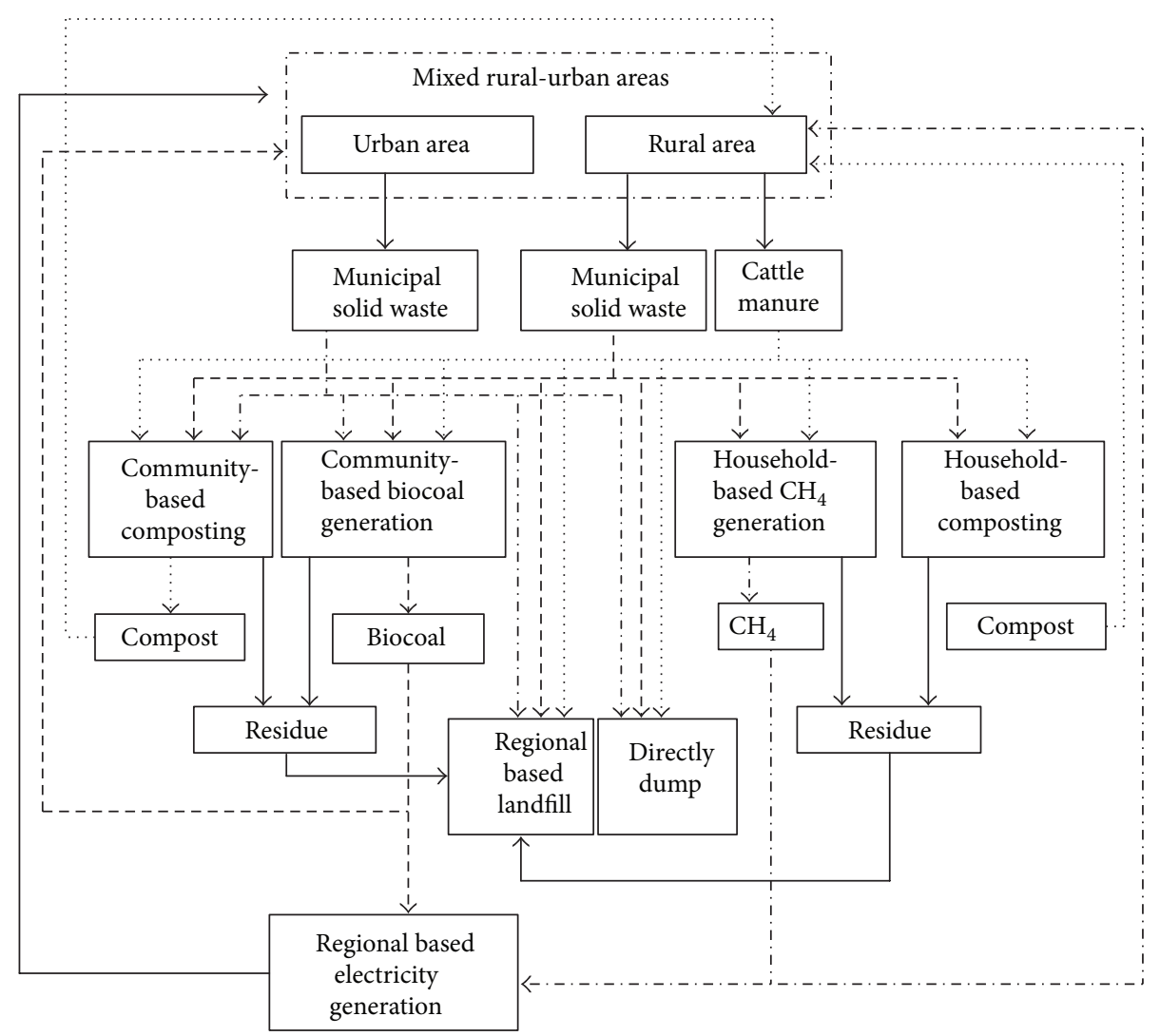

FIGURE 3: A resource-oriented solid waste management system for the mixed rural-urban area of Shuangcheng. 
TABLE 1: The operational and economic information for the existing and proposed facilities in the town of Shuangcheng.

\begin{tabular}{|c|c|c|c|c|c|c|c|}
\hline Facility & $j$ & $\begin{array}{c}\text { Capacity } \\
\text { (tonne/day) }\end{array}$ & $\begin{array}{c}\text { Running cost } \\
\text { (\$/tonne) }\end{array}$ & $\begin{array}{l}\text { Residue from } \\
\text { MSW }\end{array}$ & $\begin{array}{l}\text { Residue from } \\
\text { cattle manure }\end{array}$ & $\begin{array}{l}\text { Revenue } \\
\text { (\$/tonne) }\end{array}$ & $\begin{array}{c}\text { Transportation cost to } \\
\text { landfill (\$/tonne) } \\
\end{array}$ \\
\hline Regional based landfill & 1 & 16438 & 50 & 1 & 1 & 0 & 1 \\
\hline $\begin{array}{l}\text { Community-based biocoal } \\
\text { generation }\end{array}$ & 2 & 600 & 2000 & 0.3 & 0 & 2400 & 30 \\
\hline Community-based composting & 3 & 600 & 100 & 0.4 & 0.2 & 400 & 30 \\
\hline Household-based composting & 4 & 150 & 80 & 0.4 & 0.2 & 400 & 60 \\
\hline $\begin{array}{l}\text { Household-based } \mathrm{CH}_{4} \\
\text { generation }\end{array}$ & 5 & 150 & 80 & 0.5 & 0.3 & 500 & 60 \\
\hline Directly dump & 6 & 1 & 500 & 0 & 0 & 0 & 0 \\
\hline
\end{tabular}

$j$ is the index for the facilities used in the approach.

TABLE 2: The transportation cost from waste collecting areas to facilities.

\begin{tabular}{lccc}
\hline Area & Facility & $i j$ & Transportation cost (\$/tonne) \\
\hline Urban & Regional based landfill & 11 & 60 \\
Urban & Community-based bio-coal generation & 12 & 60 \\
Urban & Community-based composting & 13 & 60 \\
Urban & Household-based composting & 14 & 80 \\
Urban & Household-based $\mathrm{CH}_{4}$ generation & 15 & 80 \\
Urban & Directly dump & 16 & 0 \\
Rural & Regional based landfill & 21 & 60 \\
Rural & Comminity-based bio-coal generation & 22 & 30 \\
Rural & Community-based composting & 23 & 30 \\
Rural & Household-based composting & 24 & 0 \\
Rural & Household-based CH $\mathrm{CH}_{4}$ generation & 25 & 0 \\
Rural & Directly dump & 26 & 0 \\
\hline
\end{tabular}

Note: $i$ is index for the areas and $j$ is index for the facilities used in the approach.

$$
\begin{aligned}
& +\sum_{i=1}^{2} x_{i 6} P+y_{6} P \\
& -\sum_{i=1}^{2} \sum_{j=2}^{5} \mathrm{RE}_{j} x_{i j}-\sum_{j=2}^{5} \mathrm{RE}_{j} y_{j}
\end{aligned}
$$

subject to

$$
\begin{aligned}
& \sum_{j=1}^{5} x_{i j} \geq \mathrm{MG}_{i}, \quad \forall i=1,2 \\
& \sum_{j=1}^{5} y_{j} \geq \mathrm{CG} \\
& \sum_{i=1}^{2} x_{i j}+y_{j} \leq b_{j} \mathrm{CP}_{j}, \quad \forall j=2, \ldots, 6 \\
& \sum_{i=1}^{2} x_{i 1}+\sum_{i=1}^{2} \sum_{j=2}^{5} \mathrm{RM}_{j} x_{i j}+\sum_{j=2}^{5} \mathrm{RC}_{j} y_{j} \leq \mathrm{CP}_{1}
\end{aligned}
$$

$$
\begin{aligned}
& x_{i j}, y_{j} \geq 0 \\
& b_{j}=0 \text { or } 1,
\end{aligned}
$$

where

$f=$ the net system cost, $\$ / \mathrm{d}$;

$i=$ the index of area, $i=1$ for urban area and $i=2$ for rural area;

$j=$ the index of facility, $j=1,2, \ldots, 6$;

$x_{i j}=$ the municipal solid waste loading from area $i$ to facility $j$, tonne/day;

$y_{j}=$ the cattle manure loading from area $i$ to facility $j$, tonne/day;

$b_{j}=$ the binary variable for determining whether the facility $j$ will be required in the planning period: " 1 " indicates that the facility will be required to install, and " 0 " indicates that the facility is not necessary;

$\mathrm{OP}_{i}=$ the operating cost of facility $i, \$ /$ tonne;

$\mathrm{TR}_{i j}=$ the transportation cost from area $i$ to facility $j$, \$/tonne; 
$\mathrm{RM}_{j}=$ the residue rate from facility $j$ by treating municipal solid waste;

$\mathrm{RC}_{j}=$ the residue rate from facility $j$ by treating cattle manure;

$P=$ the penalty for the direct dump of waste or cattle manure, \$/tonne;

$\mathrm{MG}_{i}=$ the municipal solid waste generation rate in area $i$, tonne/day;

$\mathrm{CG}=$ the cattle manure generation rate in the town of Shuangcheng, tonne/day;

$\mathrm{CP}_{i}=$ the loading capacity of facility $j$, tonne/day;

$\mathrm{TRL}_{j}=$ the transportation cost from facility $j$ to the landfill, \$/tonne;

$\mathrm{RE}_{j}=$ the revenue generated by facility $j$ by treating the waste, $\$$ /tonne.

According to the measurement of generation rates of MSW and manure from cattle as well as the population of cattle (Figures 1 and 2), it can be determined that the dual uncertainties of possibility and continuous probability exist in waste generation. Therefore, according to the algorithm of MCFP, especially (5a)-(5f), the original model (Problem (8a) $-(8 g))$ can be converted as follows:

$$
\begin{aligned}
\operatorname{minimize} f= & \sum_{i=1}^{2} \sum_{j=1}^{5}\left(\mathrm{OP}_{j}+\mathrm{TR}_{i j}\right) x_{i j} \\
& +\sum_{j=1}^{5}\left(\mathrm{OP}_{j}+\mathrm{TR}_{2 j}\right) y_{j} \\
& +\sum_{i=1}^{2} \sum_{j=2}^{5}\left(\mathrm{OP}_{1}+\mathrm{TRL}_{j}\right) \mathrm{RM}_{j} x_{i j} \\
& +\sum_{j=2}^{5}\left(\mathrm{OP}_{1}+\mathrm{TRL}_{j}\right) \mathrm{RC}_{j} y_{j} \\
& +\sum_{i=1}^{2} x_{i 6} \mathrm{P}+y_{6} P \\
& -\sum_{i=1}^{2} \sum_{j=2}^{5} \mathrm{RE}_{j} x_{i j}-\sum_{j=2}^{5} \mathrm{RE}_{j} y_{j}+\sum_{i=1}^{2} \lambda_{i}^{1}+\lambda^{1}
\end{aligned}
$$

subject to

$$
\begin{aligned}
& \sum_{j=1}^{5} x_{i j}-\delta_{i}^{\mathrm{MG}}-\mathrm{MG}_{i}=\lambda_{i}^{1}, \quad \forall i=1,2 \\
& \sum_{j=1}^{5} y_{j}-\delta_{i}^{\mathrm{CG}}-\mathrm{CG}=\lambda^{2} \\
& \sum_{i=1}^{2} x_{i j}+y_{j} \leq b_{j} \mathrm{CP}_{j}, \quad \forall j=2, \ldots, 6
\end{aligned}
$$

$$
\begin{aligned}
& \sum_{i=1}^{2} x_{i 1}+\sum_{i=1}^{2} \sum_{j=2}^{5} \mathrm{RM}_{j} x_{i j}+\sum_{j=2}^{5} \mathrm{RC}_{j} y_{j} \leq \mathrm{CP}_{1} \\
& \lambda_{i}^{1} \leq \delta_{i}^{\mathrm{MG}}, \quad \forall i=1,2 \\
& \lambda^{2} \leq \delta^{\mathrm{CG}} \\
& x_{i j}, y_{j} \geq 0 \\
& b_{j}=0 \text { or } 1,
\end{aligned}
$$

where $\delta_{i}^{\mathrm{MG}}$ are the spreads of membership function of the MSW generation rates in Figure $2(\mathrm{a})$, which are $\delta_{1}^{\mathrm{MG}}=$ $0.1 \mathrm{~kg} /$ capita/day for the urban area based on the fuzzy membership function $t_{1}^{\mathrm{MG}}=(1.2,0.1,0.1) \mathrm{kg} /$ capita/day, and $\delta_{2}^{\mathrm{MG}}=0.05 \mathrm{~kg} / \mathrm{capita} /$ day for the rural areas based on the fuzzy membership function $t_{2}^{\mathrm{MG}}=(0.5,0.05,0.05) \mathrm{kg} /$ capita/day. $\delta^{\mathrm{CG}}$ is the spread of membership function of the manure generation rates from cattle in Figure 2(b), which is $\delta^{\mathrm{CG}}=5 \mathrm{~kg} /$ cattle/day based on the fuzzy membership function $t^{\mathrm{CG}}=(10,5,5) \mathrm{kg} /$ cattle/day.

The collected data were applied normality test by using statistical tools (i.e., Minitab), and results showed that $P$ values are greater than 0.9 . Therefore, the assumption has been made that the population and the number of cattle follow normal distributions. The population in the urban area is assumed normally distributed according to Figure 1(a), with a distribution function of $N \sim(15,1)$. While the population in the rural areas is also normally distributed according to Figure 1(b), with a distribution function of $N \sim(7,0.6)$. The number of cattle is also normally distributed according to Figure 1(c), with a distribution function of $N \sim(2.5,0.12)$. According to the distribution of parameters and the solution algorithm of MCFP, the final optimization model for solid waste management in the town of Shuangcheng can be solved by programming software (i.e., MATLAB with LINDO API).

\section{Results and Discussion}

The modeling results indicate that all MSWS from both urban and rural areas as well as the cattle manure initially flow to two facilities: the community-based bio-coal and the householdbased $\mathrm{CH}_{4}$ facilities, and then the residues from these two facilities flow to the landfill for final disposal (Figure 4). The mean values and 95\% confidence interval of the MSW flows from the urban area to the bio-coal facility are 195.1 tonne/day and "175.17, 215.63" tonne/day, respectively. The mean values and $95 \%$ confidence interval of the MSW flows from the rural area to the $\mathrm{CH}_{4}$ facility are 45.24 tonne/day and " 39.98 , 51.15" tonne/day, respectively. The mean values and $95 \%$ confidence interval of the cattle manure flows to the bio-coal facility are 270.66 tonne/day and " $250.22,291.84$ " tonne/day, respectively. The mean values and $95 \%$ confidence interval of the cattle manure flows to the $\mathrm{CH}_{4}$ facility are 104.76 tonne/day and "97.71, 110.99" tonne/day, respectively. The installations of the other proposed facilities are not suggested in the planning period. The mean values and $95 \%$ confidence interval of the optimal system cost are $\$-218,866 /$ day and 


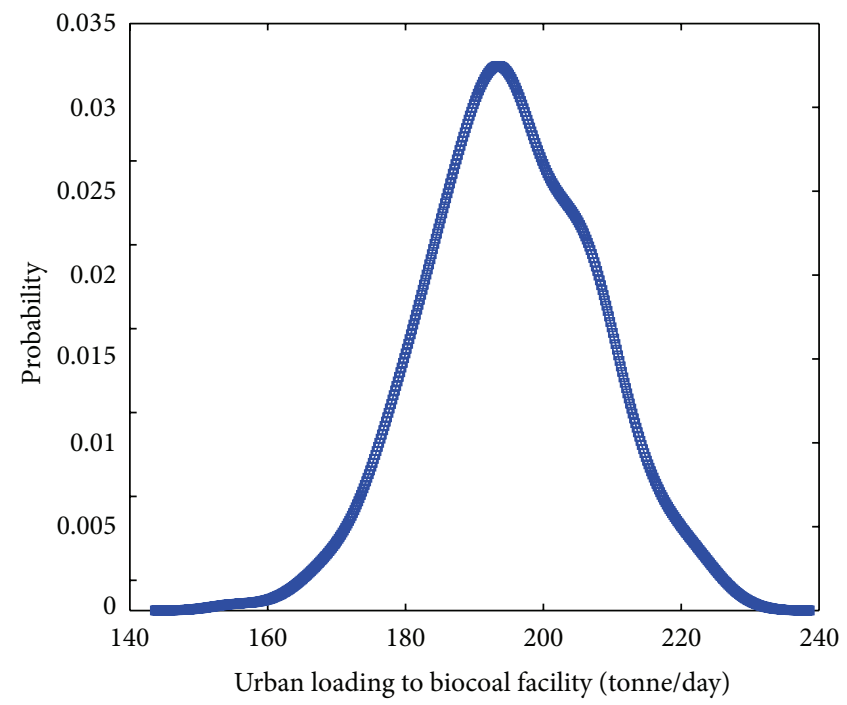

(a)

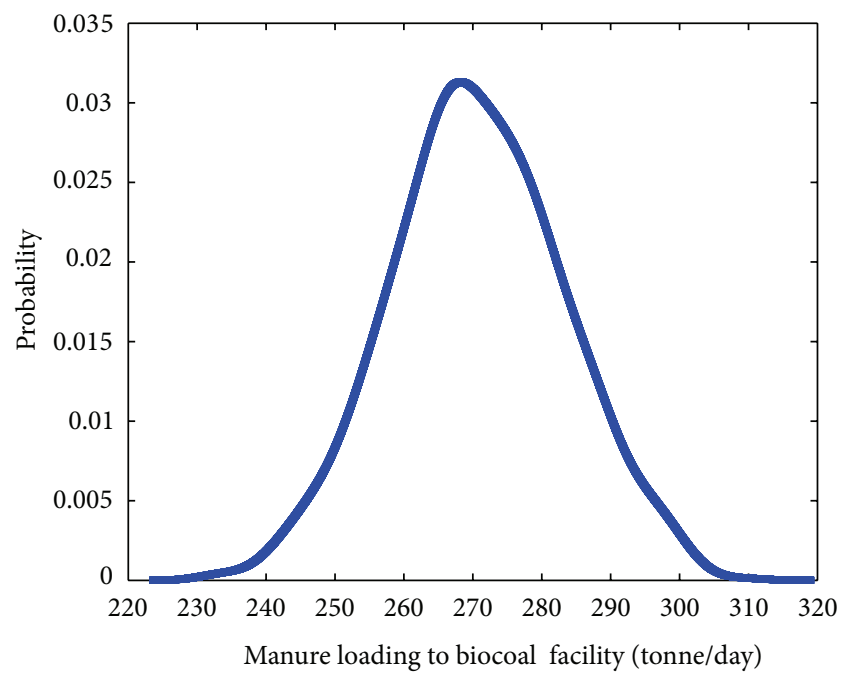

(c)

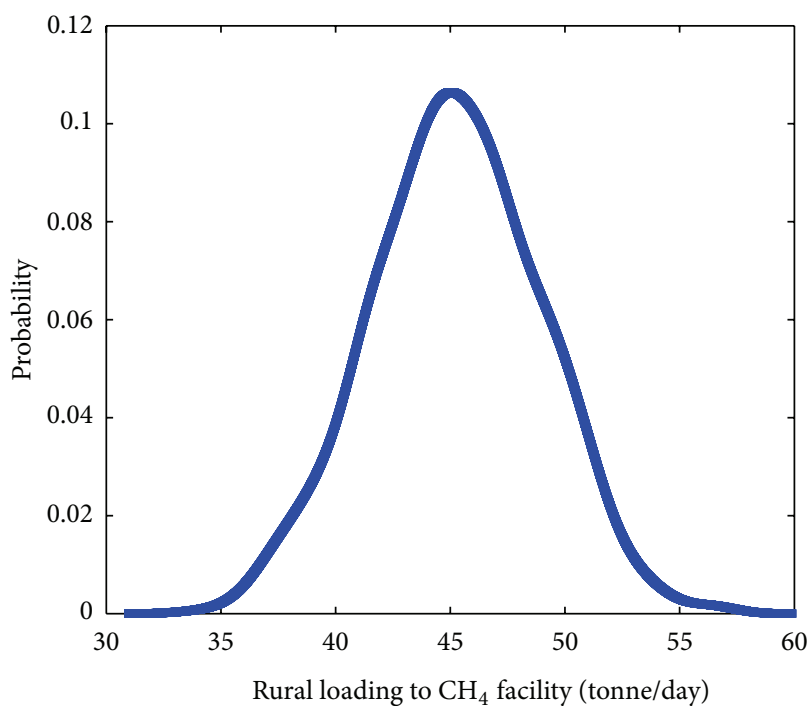

(b)

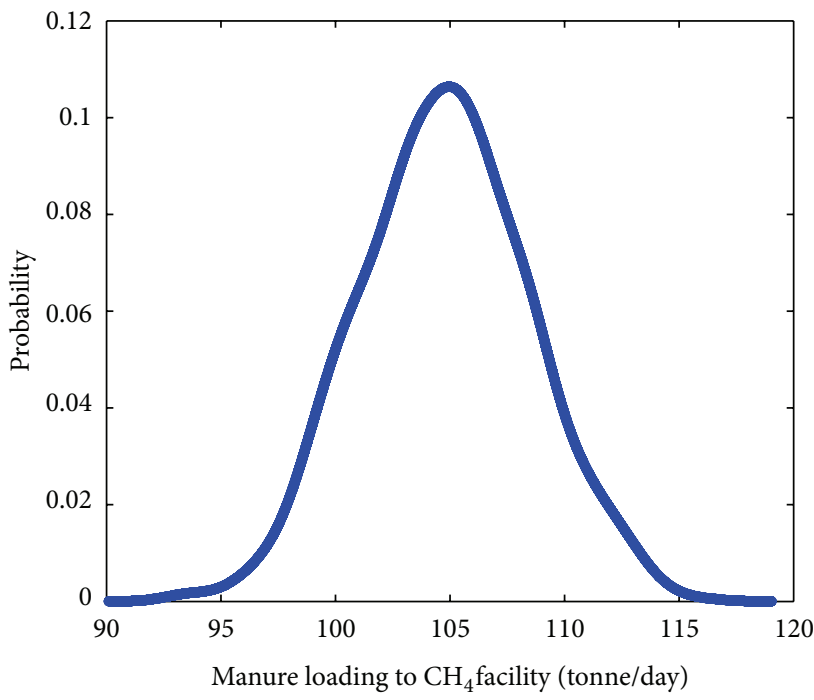

(d)

FIgURE 4: The probability distributions of (a) the MSW loading from the urban area and (c) the cattle manure loading to the communitybased biocoal facility as well as (b) the MSW loading from the rural area and (d) the cattle manure loading to the household-based $\mathrm{CH}_{4}$ facility.

“\$-229,150, $-209,010$ " day. In other words, the mean value and $95 \%$ confidence interval of the optimal system benefits are around $\$ 218.87 * 10^{3} /$ day and $\$ 209.01,229.15 * 10^{3} /$ day, respectively (Figure 5).

Since waste and cattle manure are innovatively treated in the proposed management system as a type of recycled resource, the landfill becomes the last choice for waste flow even though the running cost is the lowest. The revenue from selling the products (e.g., bio-coal and methane gas) can cover the costs of operating and maintaining the facilities such as the transportation cost for the wastes from the households to the facilities, the residues from the facilities to the landfill, and the running cost of treating the residues in the landfill, leading to net benefits to the system. This demonstrates the feasibility and sustainability of the proposed system and the potential benefits to the local community and environment.

The optimization results also indicate different loadings of the waste generated from urban and rural areas. The MSW preferentially flows to the community-based bio-coal facility and then flows to the household-based $\mathrm{CH}_{4}$ facility. For cattle manure, both the household-based $\mathrm{CH}_{4}$ facility and the community-based bio-coal facility become destinations because the net profits of these two facilities are higher than the composting facilities. Although the householdbased $\mathrm{CH}_{4}$ facility is more profitable than the communitybased bio-coal facility, the relatively high transportation cost restricts the MSW loading from the urban area to the 


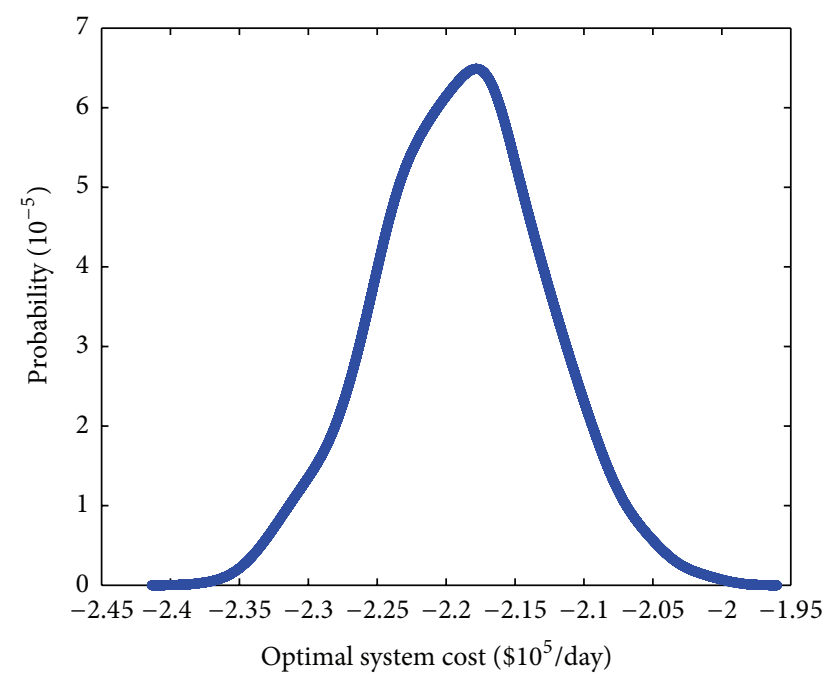

FIgURE 5: The probability distribution of the optimal system cost.

$\mathrm{CH}_{4}$ facility. In contrast, due to zero transportation cost for waste and cattle manure loading to on-site $\mathrm{CH}_{4}$ facility, this facility becomes dominant in the rural area. Similar costs are observed from the household-based composting facility and the community-based bio-coal facility with consideration of both running and transportation costs. However, there is no residue from the community-based bio-coal facility, while about $20 \%$ of residue from the household-based composting facility, eventually leading to additional costs in transferring and operating the residue from the composting facility to the landfill. Therefore, some portions of cattle manure are optimally loaded to the community-based bio-coal facility.

Based on the above results, it is recommended either to increase the capacity of household-based $\mathrm{CH}_{4}$ facility to digest all the waste and cattle manure from the rural area and locate the community-based bio-coal facility closer to the town of Shuangcheng or to keep the current capacity of the household-based $\mathrm{CH}_{4}$ facility and locate the communitybased bio-coal facility between the urban and rural areas. However, because the household-based $\mathrm{CH}_{4}$ facility is easier and more economical to install and operate (many households in the town of Shuangcheng already have $\mathrm{CH}_{4}$ pits installed), it is more profitable to increase the capacity of the household-based $\mathrm{CH}_{4}$ facility.

In order to further minimize the system cost or maximize the system net profit, series of MCFP optimization processes have been applied by changing the capacity of householdbased $\mathrm{CH}_{4}$ facility from 150 to 600 tonne/day with increments of 50 tonne/day. The results (Figures 6 to 11) indicate that the optimal system cost keeps decreasing when the capacity of household-based $\mathrm{CH}_{4}$ facility increases from 150 to 450 tonne/day. When the capacity of $\mathrm{CH}_{4}$ facility is 450 tonne/day, the system cost becomes the lowest $\left(\$-2.23 * 10^{5} /\right.$ day). After this optimal point, the system cost increases again, which is because capacity of the facility is overdesigned and extra maintenance and operational cost will be required (Figure 9).

The loading of cattle manure to the community-based bio-coal facility keeps decreasing; meanwhile, the loading to

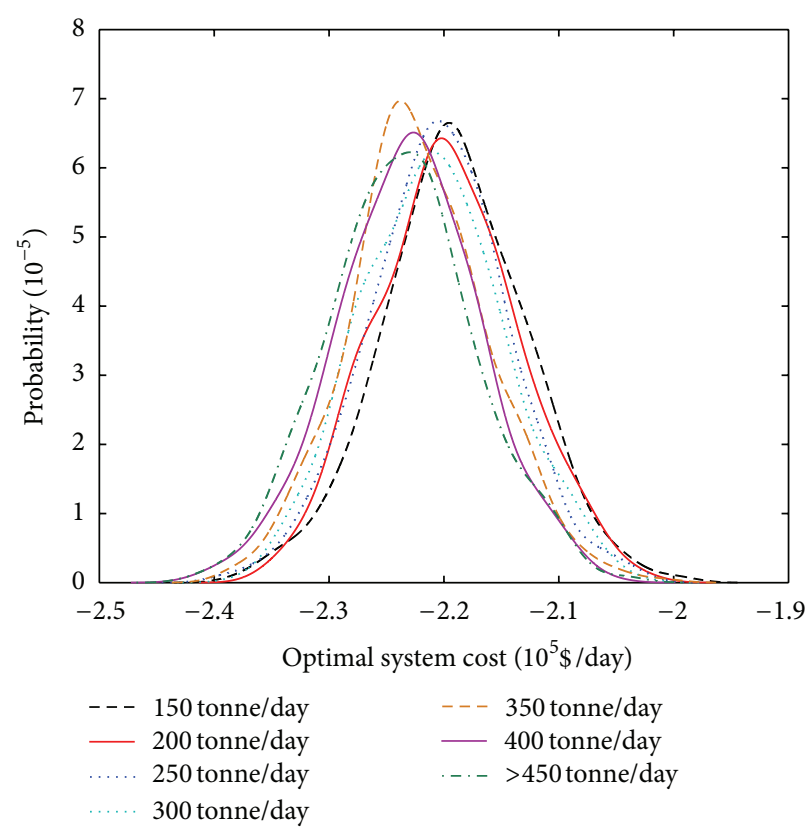

FIGURE 6: Probability distributions of optimal system cost with the changing capacity of the household-based $\mathrm{CH}_{4}$ facility.

the household-based $\mathrm{CH}_{4}$ facility keeps increasing due to its growing capacity. If the capacity of the household-based $\mathrm{CH}_{4}$ facility is equal or higher than 450 tonne/day, all the waste from the rural area will be treated to produce $\mathrm{CH}_{4}$ as the renewable energy source (Figures 9 and 11).

Because the community-based bio-coal facility is dominant in the urban waste flow, the capacity change of household-based $\mathrm{CH}_{4}$ facility does not affect the MSW loading from the urban area to the community-based bio-coal facility (Figures 7(a) and 10(a)). In contrast, the householdbased $\mathrm{CH}_{4}$ facility is dominant in the rural waste (both municipal solid waste from the rural area and the cattle manure) flow. Because the capacity of the $\mathrm{CH}_{4}$ facility is always higher than the total loading of the rural MSW which has the highest priory in flowing to the facility, the rural MSW loading to this facility does not have notable changes with the capacity change of the facility (Figures 7(b) and 10(b)).

Compared with the loading of cattle manure to the community-based bio-coal facility, the loading to the household-based $\mathrm{CH}_{4}$ facility is dominant. When the capacity of the household-based $\mathrm{CH}_{4}$ facility is limited for all the loadings of MSW and the cattle manure from the rural area, the extra cattle manure will hypothetically flow to the community-based bio-coal facility. Therefore, with the increasing capacity of the household-based $\mathrm{CH}_{4}$ facility, the loading of cattle manure to the community-based bio-coal facility keeps decreasing and the loading to the household-based $\mathrm{CH}_{4}$ facility keeps increasing. In addition, when the capacity of the household-based $\mathrm{CH}_{4}$ facility is equal or higher than 450 tonnes/day, all the wastes from the rural area (MSW and cattle manure) will be delivered to this facility (Figures 8 and 11). 


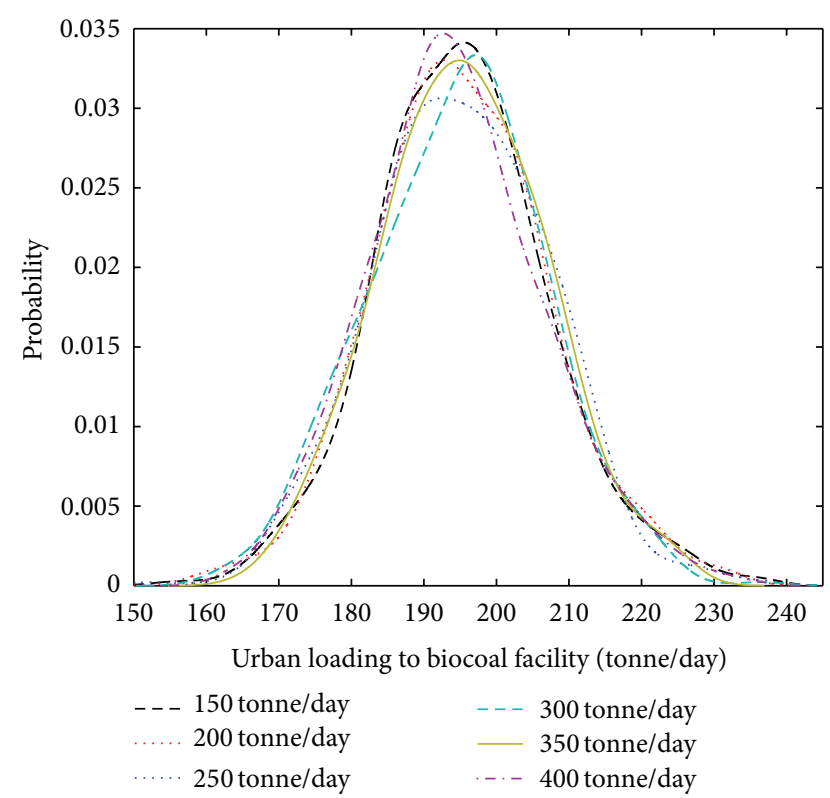

(a)

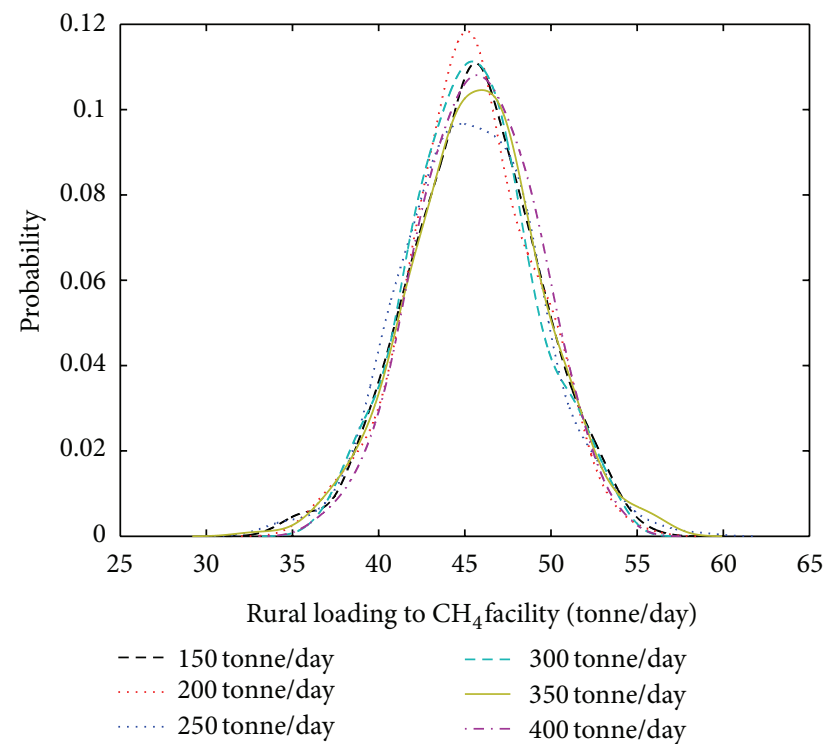

(b)

FIgURE 7: Probability distributions of optimal MSW loadings (a) from the urban area to the community-based bio-coal facility and (b) from the rural area to the household-based $\mathrm{CH}_{4}$ facility with the changing capacity of household-based $\mathrm{CH}_{4}$ facility.

In the case study, 1,000 trials were applied for the Monte Carlo simulation, and optimization results were obtained from 935 trials. The high ratio of optimization results achievement demonstrates a high feasibility of the model setting with the coverage of corresponding uncertainties. In the case that the model is infeasible (e.g., some constraints in the model conflict with the others), no solution can be obtained for the optimization. This situation is very common in many traditional optimization models (e.g., traditional fuzzy programming) considering multiple features

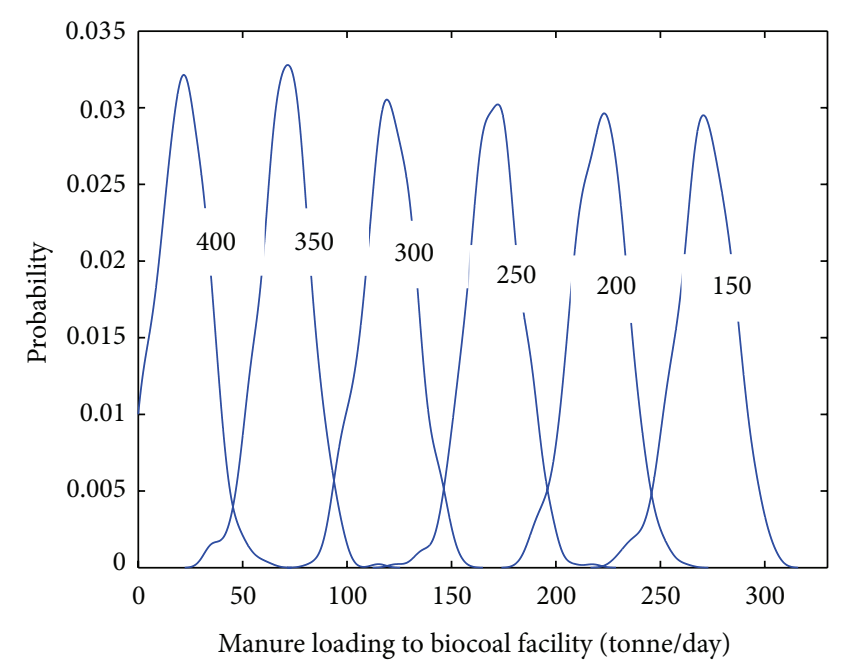

(a)

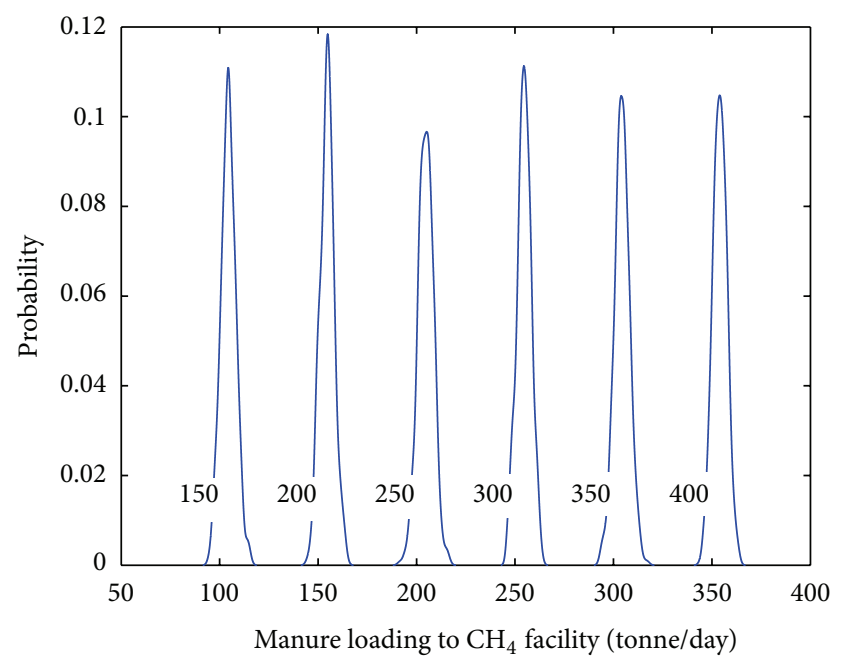

(b)

FIgURE 8: Probability distributions of optimal cattle manure loadings to (a) the community-based bio-coal facility and (b) the household-based $\mathrm{CH}_{4}$ facility with the changing capacity of the household-based $\mathrm{CH}_{4}$ facility.

in complex systems (e.g., the system in the case study of this paper). With the consideration of the full range of uncertain conditions, the proposed approach can obtain as many optimal solutions as possible under various conditions with uncertainty and complexity, making it more advantage from the traditional models. It is also worthwhile noting that the solutions can provide three types of decision to support decision makers at different levels to regulate, design, manage, and operate the solid waste management system. Firstly, the optimal distributions of the system investment or cost (Figure 5) with the corresponding waste and cattle manure flows (Figure 4) can provide a complete and clear image to local authorities. This can help legislate or amend related policies and regulations and further develop sound strategies for the resource oriented solid waste management in a mixed rural-urban area. Secondly, the ranges of most 


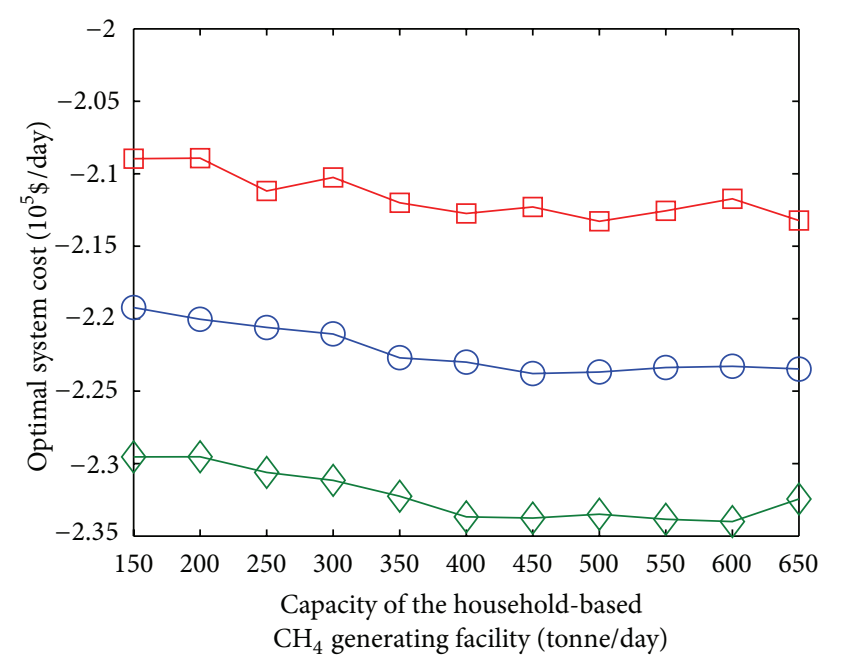

$$
\begin{aligned}
& \nabla \text { Lowerbound of the } 95 \% \text { confidence interval } \\
& \checkmark \text { Mean value } \\
& \square \text { Upperbound of the } 95 \% \text { confidence interval }
\end{aligned}
$$

FIGURE 9: Changes of optimal system cost with the changing capacity of the household-based $\mathrm{CH}_{4}$ facility.

frequent occurrences (the 95\% confidence intervals) can assist facility managers to flexibly and effectively develop the production/treatment schedules for different facilities. Thirdly, the expected values of the optimal system cost with corresponding settings (the average loadings) can be used by facility operators (including individual farmers and their groups) to optimize their productions/profits regarding the solid waste management.

\section{Conclusions}

This study developed a resource-oriented solid waste management system for a mixed rural-urban area. The system was featured by a resource-oriented management framework and a Monte Carlo simulation-based fuzzy programming (RSW-MCFP). The resource-oriented solid waste management concept was adopted for formation and enhancement of the household and community stewardships and further supported by the optimization of energy, resources, capital, and waste flows under uncertainties. The cooperative stewardship was well reflected through resource-oriented waste treatment and cyclic economy development, leading to the independence and sustainability of the management system and local economy. The system could emphasize stewardship over the life span of solid waste including generation, collection, reusing, recycling, recovery, treatment, and final disposal. Therefore, based on the assumption that the optimum solution path is always followed in the real-world application, the system could help optimize the total internal waste flow and utilization recycling to achieve maximum economic and environmental benefits in a mixed rural-urban area.

The adopted Monte Carlo simulation-based fuzzy programming (MCFP) approach determined the waste flow to

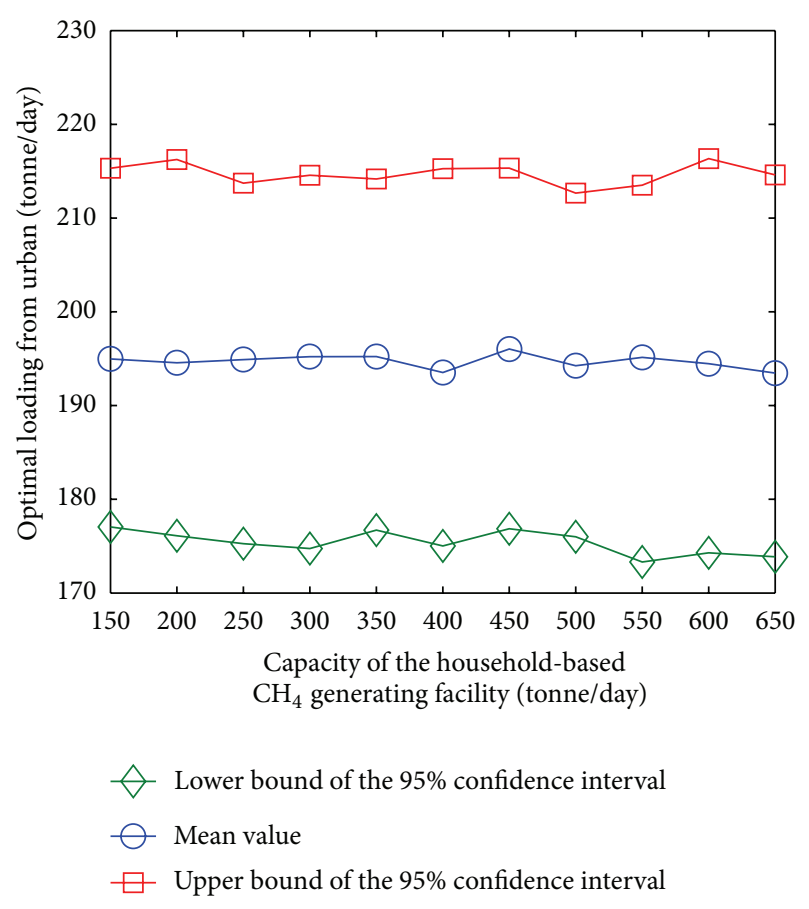

(a)

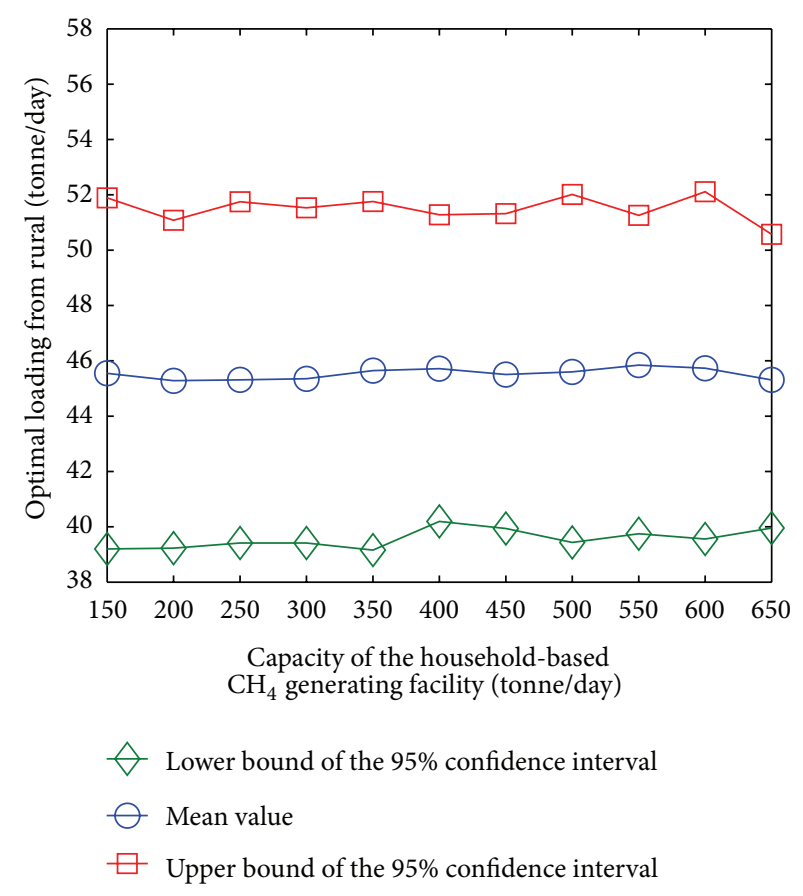

(b)

FIGURE 10: Changes of optimal MSW loading (a) from the urban area to the community-based bio-coal facility and (b) from the rural area to the household-based $\mathrm{CH}_{4}$ facility with the changing capacity of household-based $\mathrm{CH}_{4}$ facility.

the waste treatment and disposal facilities and supported the decision-making process in determining the optimal management strategy under uncertainties. This approach could efficiently convert fuzzy problems to deterministic ones and achieve the optimal solutions with fewer additional 


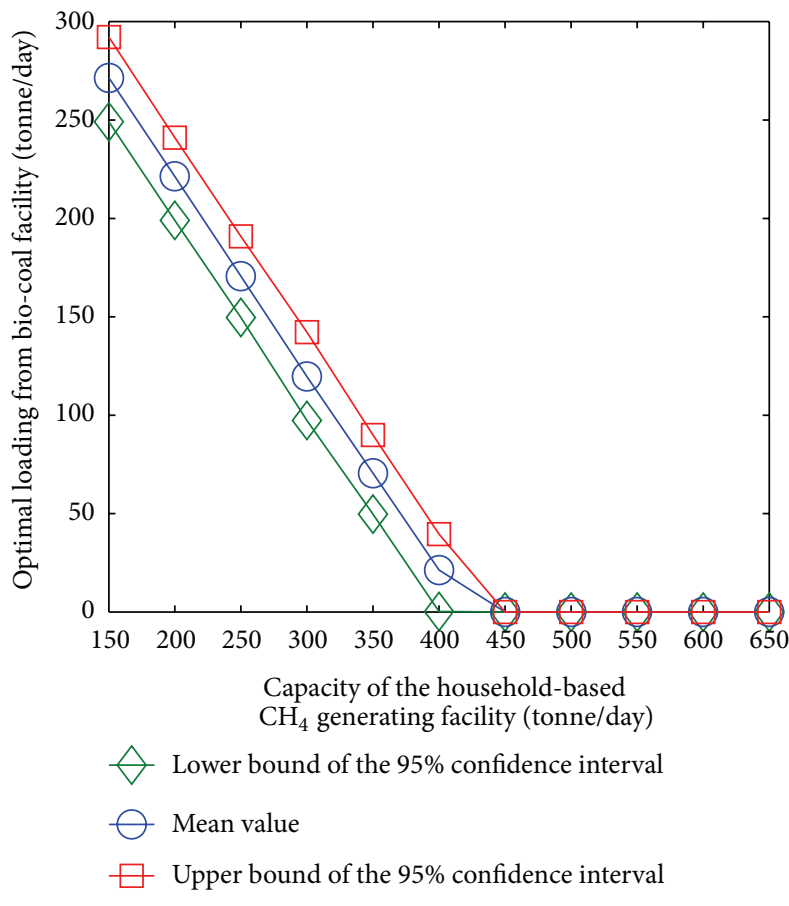

(a)

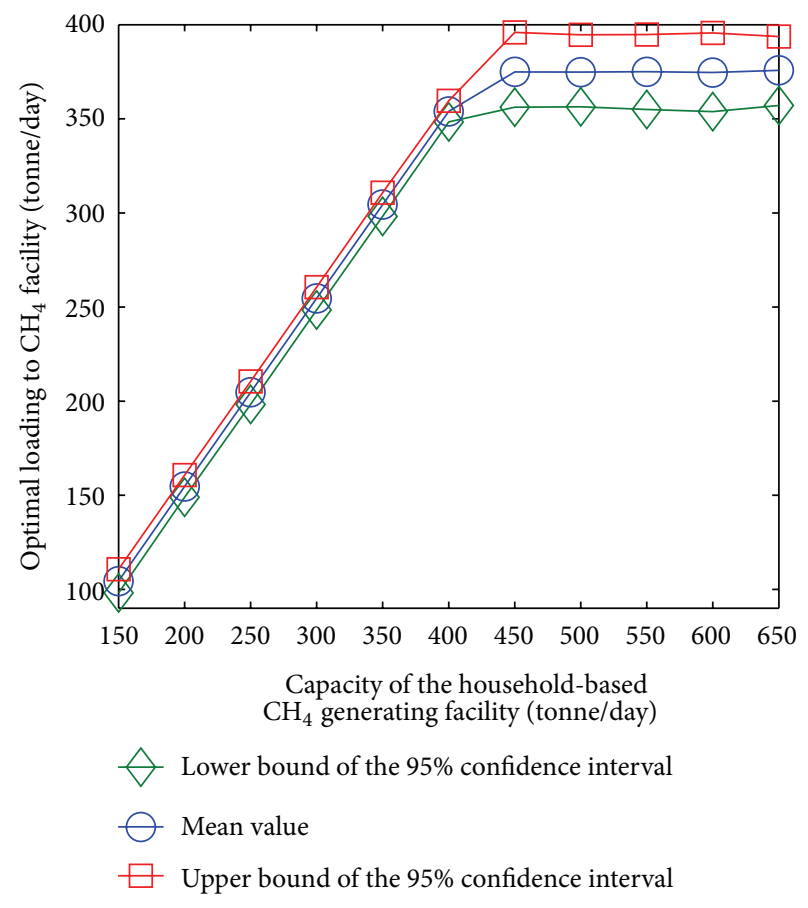

(b)

FIGURE 11: Changes of optimal cattle manure loadings to (a) the community-based bio-coal facility and (b) the household-based $\mathrm{CH}_{4}$ facility with the changing capacity of the household-based $\mathrm{CH}_{4}$ facility.

constraints, leading to significant reductions in system complexity and computational efforts. These advantages could help fuzzy programming easily and efficiently integrate with Monte Carlo simulation. Consequently, the MCFP approach could effectively tackle the coexistence of uncertainties in forms of fuzzy sets and continuous probability distributions.

The developed RSW-MCFP system was tested by a realworld application of solid waste management in the town of Shuangcheng, Northeast China. The modeling results indicated that the community-based bio-coal facility and the household-based $\mathrm{CH}_{4}$ facility would be predominant in the management system and recommended increasing the capacity of the household-based $\mathrm{CH}_{4}$ facility to digest all the municipal solid waste from the rural area and cattle manure in the mixed rural-urban area. The results also suggested locating the community-based bio-coal facility close to the urban area. In addition, the developed system could provide three levels of the optimal results to help decision makers effectively manage the system facilities. The first level included the entire distributions of objective functions and decision variables, which could provide decision support to general policy makers (e.g., regulating and consulting organizations) for long-term policy making and trade-off, risk, and reliability analyses of the system. The second level included the ranges of most frequent occurrences, which could help project or system managers design and plan the production in a medium arrangement. The third level indicated the expected values of the optimal results, which could directly provide decision alternatives to the system operators for short-term operation (e.g., adjusting the facility to minimize system cost).
The based assumption of the case study in this stage is that the resource or money flow was only driven by the profit, which may not occur in reality. Future study will focus on analyzing and reflecting the complex relations in the market in the developed system. In addition, the purpose of this case study is to provide decision support for the future planning of solid waste system. Most of the facilities in the proposed system are yet to be installed, making the results difficult to be analysed by solid evidence. The collection of detailed information regarding the proposed facilities will further conduct to make the approach more applicable in real-world decision making. Future studies are also expected to closely investigate the interactions and collective effects under different system conditions, providing optimal alternatives in managing key elements for a robust and sustainable development of solid waste industries.

\section{Conflict of Interests}

The authors of this manuscript do not have any direct financial relation with the commercial identities mentioned in the paper (i.e., Minitab, MATLAB, and LINDO API) that might lead to a conflict of interest.

\section{Acknowledgments}

The study was supported by the National Natural Science Foundation of China (51179070), Natural Science and Engineering Research Council of Canada, and United Nations Development Programme (UNDP) as well as the China International Center for Economic and Technical Exchanges (CICETE) of the Ministry of Commerce of China. 


\section{References}

[1] A. Singh, "Municipal solid waste management in Jaipur: current status and way forward," Rajasthan State Pollution Control Board 4, Institutional Area, Jhalana Doongri, Jaipur, India, 2010.

[2] B. Chen, P. Li, and H. J. Wu, "MCFP: a Monte Carlo simulation based fuzzy programming approach for municipal solid waste management under dual uncertainties of possibility and continuous probability," Engineering Optimization. In press.

[3] G. H. Huang and N. B. Chang, "The perspectives of environmental informatics and systems analysis," Journal of Environmental Informatics, vol. 1, no. 1, pp. 1-7, 2003.

[4] S. Wang, G. H. Huang, and B. T. Yang, "An interval-valued fuzzy-stochastic programming approach and its application to municipal solid waste management," Environmental Modelling and Software, vol. 29, no. 1, pp. 34-36, 2011.

[5] G. H. Huang, B. W. Baetz, and G. G. Patry, "A grey fuzzy linear programming approach for municipal solid waste management planning under uncertainty," Civil Engineering and Environmental Systems, vol. 10, no. 2, pp. 123-146, 1993.

[6] B. Chen, H. Guo, G. Huang, Y. Yin, and B. Zhang, "IFMEP: an interval fuzzy multiobjective environmental planning model for urban systems," Civil Engineering and Environmental Systems, vol. 25, no. 2, pp. 99-125, 2008.

[7] Y. Gunalay, J. S. Yeomans, and G. H. Huang, "Modeling to generate alternative policies in highly uncertain environments: an application to municipal solid waste management planning," Journal of Environmental Informatics, vol. 19, no. 2, pp. 58-69, 2012.

[8] P. Li, B. Chen, B. Y. Zhang, and L. Jing, "A new agro-industrial waste management model for supporting rural co-operative stewardship and sustainable development," in Proceeding of the 3rd International Scientific Conference on Industrial and Hazardous Waste Management, Chania, Greece, 2012.

[9] Y. P. Li, G. H. Huang, Y. F. Huang, and H. D. Zhou, "A multistage fuzzy-stochastic programming model for supporting sustainable water-resources allocation and management," Environmental Modelling and Software, vol. 24, no. 7, pp. 786-797, 2009.

[10] P. Li and B. Chen, "FSILP: fuzzy-stochastic-interval linear programming for supporting municipal solid waste management," Journal of Environmental Management, vol. 92, no. 4, pp. 11981209, 2011.

[11] Z. S. Li, H. Z. Fu, and X. Y. Qu, "Estimating municipal solid waste generation by different activities and various resident groups: a case study of Beijing," Science of the Total Environment, vol. 409, no. 20, pp. 4406-4414, 2011.

[12] J. Ramik and M. Vlach, "Fuzzy mathematical programming: a unified approach based on fuzzy relations," Fuzzy Optimization and Decision Making, vol. 1, no. 4, pp. 335-346, 2002.

[13] Y. P. Cai, G. H. Huang, X. H. Nie, Y. P. Li, and Q. Tan, "Municipal solid waste management under uncertainty: a mixed interval parameter fuzzy-stochastic robust programming approach," Environmental Engineering Science, vol. 24, no. 3, pp. 338-352, 2007.

[14] Z. F. Liu, G. H. Huang, R. F. Liao, and L. He, "DIPIP: dual interval probabilistic integer programming for solid waste management," Journal of Environmental Informatics, vol. 14, no. 1, pp. 66-73, 2009.

[15] G. H. Lin, X. Chen, and M. Fukushima, "Solving stochastic mathematical programs with equilibrium constraints via approximation and smoothing implicit programming with penalization," Mathematical Programming, vol. 116, no. 1-2, pp. 343-368, 2009.

[16] Y. Xu, G. H. Huang, X. S. Qin, and Y. Huang, "SRFILP: a stochastic robust fuzzy interval linear programming model for municipal solid waste management under uncertainty," Journal of Environmental Informatics, vol. 14, no. 2, pp. 74-82, 2009.

[17] S. Galelli and R. Soncini-Sessa, "Combining metamodelling and stochastic dynamic programming for the design of reservoir release policies," Environmental Modelling and Software, vol. 25, no. 2, pp. 209-222, 2010.

[18] P. Guo, G. H. Huang, H. Zhu, and X. L. Wang, "A twostage programming approach for water resources management under randomness and fuzziness," Environmental Modelling and Software, vol. 25, no. 12, pp. 1573-1581, 2010.

[19] Y. P. Li, G. H. Huang, and W. Sun, "Management of uncertain information for environmental systems using a multistage fuzzy-stochastic programming modle with soft constraints," Journal of Environmental Informatics, vol. 18, no. 1, pp. 28-37, 2011.

[20] X. S. Qin and G. H. Huang, "Characterizing uncertainties associated with contaminant transport modeling through a coupled fuzzy-stochastic approach," Water, Air, and Soil Pollution, vol. 197, no. 1-4, pp. 331-348, 2009.

[21] A. L. Yang, G. H. Huang, and X. S. Qin, "An integrated simulation-assessment approach for evaluating health risks of groundwater contamination under multiple uncertainties," Water Resources Management, vol. 24, no. 13, pp. 3349-3369, 2010.

[22] A. N. Blair, B. M. Ayyub, and W. J. Bender, "Fuzzy stochastic risk-based decision analysis with the mobile offshore base as a case study," Marine Structures, vol. 14, no. 1-2, pp. 69-88, 2001.

[23] P. Seuntjens, "Field-scale cadmium transport in a heterogeneous layered soil," Water, Air, and Soil Pollution, vol. 140, no. 1-4, pp. 401-423, 2002.

[24] C. Baudrit, D. Guyonnet, and D. Dubois, "Joint propagation of variability and imprecision in assessing the risk of groundwater contamination," Journal of Contaminant Hydrology, vol. 93, no. 1-4, pp. 72-84, 2007.

[25] J. B. Li, G. H. Huang, G. Zeng, I. Maqsood, and Y. Huang, "An integrated fuzzy-stochastic modeling approach for risk assessment of groundwater contamination," Journal of Environmental Management, vol. 82, no. 2, pp. 173-188, 2007.

[26] G. H. Cheng, G. H. Huang, Y. P. Li, M. F. Cao, and Y. R. Fan, "Planning of municipal solid waste management systems under dual uncertainties: a hybrid interval stochastic programming approach," Stochastic Environmental Research and Risk Assessment, vol. 23, no. 6, pp. 707-720, 2009.

[27] L. Liu, S. Y. Cheng, and H. C. Guo, "A simulation-assessment modeling approach for analyzing environmental risks of groundwater contamination at waste landfill sites," Human and Ecological Risk Assessment, vol. 10, no. 2, pp. 373-388, 2004.

[28] J. B. Li, L. Liu, G. H. Huang, and G. Zeng, "A fuzzy-set approach for addressing uncertainties in risk assessment of hydrocarboncontaminated site," Water, Air, and Soil Pollution, vol. 171, no. 1-4, pp. 5-18, 2006.

[29] Y. P. Li and G. H. Huang, "Dual-interval fuzzy stochastic programming method for long-term planning of municipal solid waste management," Journal of Computing in Civil Engineering, vol. 24, no. 2, pp. 188-202, 2010.

[30] Y. P. Li, G. H. Huang, and S. L. Nie, "A mathematical model for identifying an optimal waste management policy under 
uncertainty," Applied Mathematical Modelling, vol. 36, no. 6, pp. 2658-2673, 2012.

[31] T. Li, P. Li, B. Chen, M. Hu, and X. Zhang, "A simulation-based inexact two-stage chance constraint quadratic programming for sustainable water quality management under dual uncertainties," Journal of Water Resources Planning and Management, 2012.

[32] D. Guyonnet, B. Bourgine, D. Dubois, H. Fargier, B. Côme, and J. P. Chilès, "Hybrid approach for addressing uncertainty in risk assessments," Journal of Environmental Engineering, vol. 129, no. 1, pp. 68-78, 2003.

[33] M. Goldstein, "Subjective Bayesian analysis: principles and practice," Bayesian Analysis, vol. 1, no. 3, pp. 403-420, 2006.

[34] R. A. Freeze, H. Massmann, L. Smith, T. Sperling, and B. James, "Hydrogeological decision analysis: 1. A framework," Ground Water, vol. 28, no. 5, pp. 738-766, 1990.

[35] D. Vose, Quantitative Risk Analysis: A Guide to Monte Carlo Simulation Modelling, John Wiley \& Sons, Hoboken, NJ, USA, 1996.

[36] P. H. Garthwaite, J. B. Kadane, and A. O’Hagan, "Statistical methods for eliciting probability distributions," Journal of the American Statistical Association, vol. 100, no. 470, pp. 680-701, 2005.

[37] I. Baud, S. Grafakos, M. Hordijk, and J. Post, "Quality of life and alliances in solid waste management. Contributions to Urban sustainable development," Cities, vol. 18, no. 1, pp. 3-12, 2001.

[38] M. N. U. Mia, Product stewardship and stakeholder participation in solid waste management: a New Zealand study [M.S. thesis], Department of Social Science, Auckland University of Technology, 2011.

[39] N. V. Hop, "Fuzzy stochastic goal programming problems," European Journal of Operational Research, vol. 176, no. 1, pp. 7786, 2007.

[40] Statistic Bureau of the City of Shuangcheng, Statistics of Society and Economy of the City of Shuangcheng from 2000 to 2007, Statistic Bureau of the City of Shuangcheng, Heilongjiang, China, 2010.

[41] Environmental Monitoring Station of the City of Shuangcheng, Environmental Quality Outline of ShuangCheng-2008, Environmental Monitoring Station of the City of Shuangcheng, Heilongjiang, China, 2009.

[42] Environmental Monitoring Station of the City of Shuangcheng, Environmental Quality Outline of ShuangCheng-2009, Environmental Monitoring Station of the City of Shuangcheng, Heilongjiang, China, 2010. 


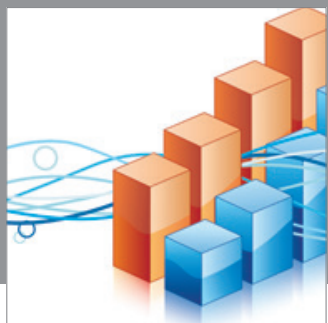

Advances in

Operations Research

mansans

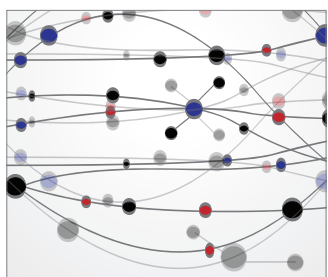

The Scientific World Journal
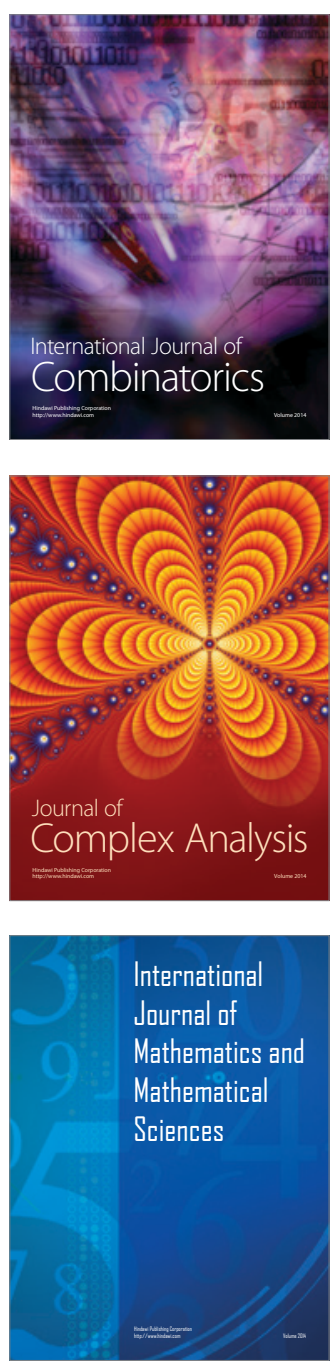
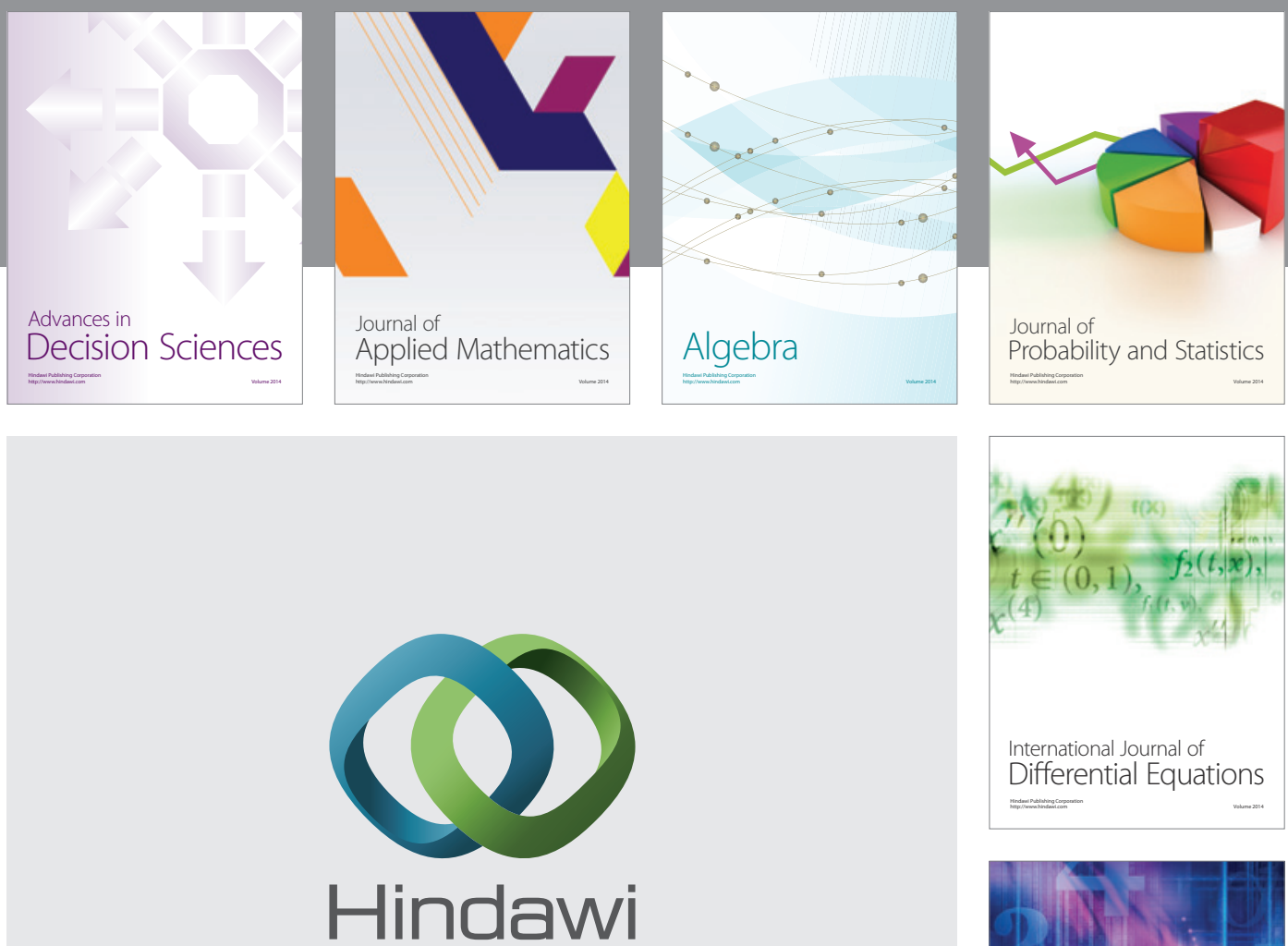

Submit your manuscripts at http://www.hindawi.com
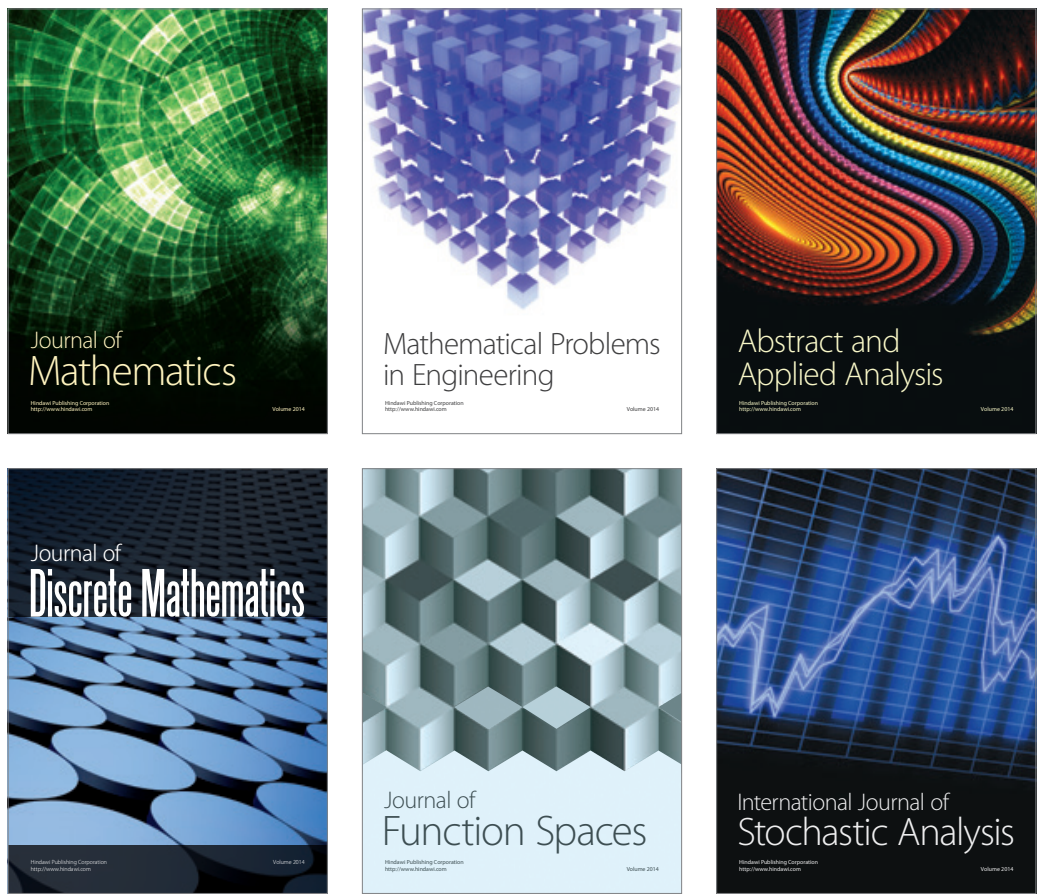

Journal of

Function Spaces

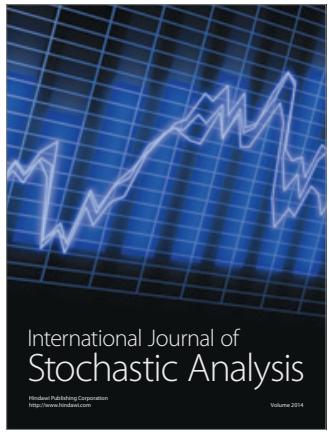

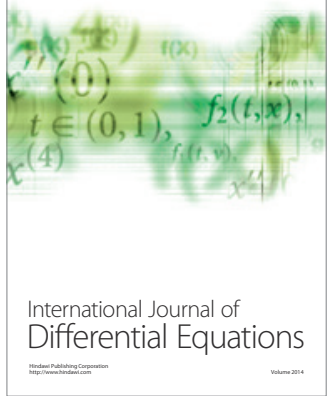
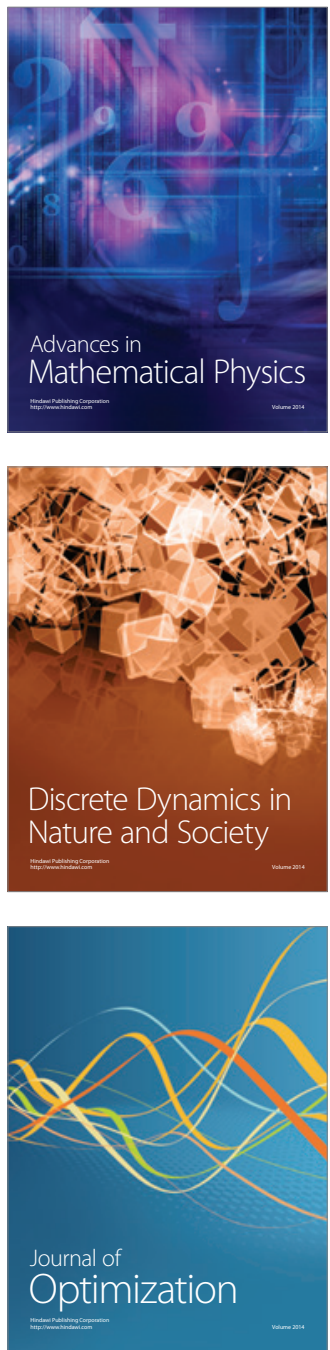